\title{
Site-specific Ultimate Limit State Fragility of Offshore Wind Turbines on Monopile Substructures
}

\author{
David Wilkie $^{1 *}$ and Carmine Galasso ${ }^{1}$ \\ ${ }^{1}$ Department of Civil Environmental \& Geomatic Engineering, University College London, \\ $\mathrm{UK}$ \\ * E-mail: david.wilkie.15@ucl.ac.uk
}

\begin{abstract}
Assessing the risk posed by severe storms to offshore wind turbines (OWTs) is a challenging task. Stochastic environmental conditions represent the main source of variable loading; consequently, a high level of uncertainty is associated with assessing structural demand on OWT structures. Failure of any of the primary structural components implies both complete loss of the OWT and loss of earnings associated with production stoppage. In this paper, we propose the use of a probabilistic risk modelling framework to assess the structural risk posed by extreme weather conditions to OWTs. To achieve this, fragility functions are developed for OWTs on monopile foundations exposed to extreme metocean conditions using dynamic aeroelastic simulations. Structural fragility represents a key component of any probabilistic risk model and expresses the likelihood of different levels of damage experienced by an OWT over a range of wind and wave hazard intensities. We compare the effect of various modelling and analysis choices on the obtained fragility functions and investigate potential interdependencies between failure modes of OWT structural components. Results from this study highlight how different assumptions affect the estimated structural performance and the resulting structural fragility of a case-study OWT. We apply the proposed framework to two case-study sites, one in the USA East Coast and one in the North Sea, discussing possible outcomes of the proposed framework.
\end{abstract}

\section{Introduction and motivations}

Offshore wind energy is experiencing rapid worldwide development as an attractive renewable energy source. The global offshore wind industry has grown to approximately $18 \mathrm{GW}$ of capacity [1]. Europe provides $15.8 \mathrm{GW}$ of this [2], with a further $25 \mathrm{GW}$ worth of projects due to be installed by 2020 [2]. Additionally, there are plans to build more offshore wind farms (OWFs) in Asia, with the Japanese Wind Power Association having established a roadmap for deployment [3] and the Chinese government setting capacity targets [4]; and along the USA East Coast [1]. One of the key challenges in designing offshore structures - or in assessing existing ones - lies in estimating environmental loading, which for offshore wind turbines (OWTs) is a result of site-specific wind and wave conditions that are expected to be encountered during the life of the structure. These conditions can include severe typhoons in Asia, hurricanes in the USA, and extra-tropical cyclones (windstorms) in Europe. Indeed, failure of towers and blades of smaller onshore wind turbines has been observed as a result of recent typhoons in China [5], where hub-height 10-minute averaged wind speeds in excess of $60 \mathrm{~m} / \mathrm{s}$ were recorded. The higher cost and difficulty in repairing OWTs means that accurately assessing their risk of failure is especially important. The design and assessment of OWTs is currently based on semi-probabilistic prescriptive approaches, described in International Electrotechnical Commission (IEC) 61400-3 code [6] and in DNVGL-ST-0126 [7]. These standards employ the load-resistance factor design (LRFD) approach to guarantee a certain safety level in structural components. Additionally, both the IEC and DNVGL standards specify ultimate limit state (ULS) design load cases (DLC) characterized by an upper limit of 50 -year mean return period (MRP) wind and wave conditions. This is substantially lower than the maximum MRP of 10,000 years utilized in LRFD codes to assess offshore oil and gas 
structures $[8,9]$. In other words, it is possible that current design procedures do not sufficiently consider rare, but severe, storm conditions characterized by higher MRP, such as the typhoon conditions observed to cause failure of onshore wind turbines [5]. Furthermore, the safety levels implied by standards are not always intelligible to design engineers. Specifically, safety factors are employed to account for uncertainties affecting structural demand and capacity, and to ensure 'safe' designs over a range of limit states depending on the severity of the consequences associated with structural failure. For OWTs these safety factors are often adapted from the offshore oil and gas industry or from design guidelines for onshore wind turbines: they have not been specifically calibrated for OWTs. Poor characterisation of these uncertainties, when assessing the actual risk profile of an OWT, could produce design solutions that are either too conservative (and not cost-effective) or unsafe, leading to potentially catastrophic losses such as those that would be caused by a large number of cascading failures in an OWT or even an OWF. Quantifying these different sources of uncertainty poses significant technical challenges but could also aid the financing and insuring of offshore projects [10], potentially helping to reduce the levelized electricity cost for offshore wind [11], i.e., the average total cost to build and operate an asset over its lifetime divided by the total energy output of the asset over that lifetime.

A framework based on probabilistic risk modelling is proposed here to assess structural and, potentially, non-structural risk associated with OWTs exposed to extreme weather conditions. This approach can be used in principle 1) to test new design strategies - extending performancebased design frameworks to account for multiple hazards; 2) to devise efficient and targeted asset management strategies; and 3) to develop resilience-enhancing solutions for combined wave and wind hazards, e.g. based on structural health monitoring and structural control. These options all rely on better assessing the risks associated with OWFs/OWTs, including a better characterization of the uncertainties in structural modelling and analysis. Figure 1 shows the basic structure of a probabilistic risk model which has been specifically adapted for application to OWFs. The overall framework can be decomposed into a series of sequential components [12]: 1) exposure information about asset location, physical construction details (e.g., structural properties such as geometry, materials, and uncertainty models), and replacement costs (i.e., asset value); 2) estimation of relevant hazard intensities and their recurrence periods at each affected site, for instance based on large catalogues of simulated events capturing the frequency, severity, location, and other characteristics of the entire spectrum of plausible real events (event generation). For each simulated event, the intensity of the hazard is then calculated at each affected site (local intensity calculation); 3) estimation of the structural response given hazard intensities through structural analysis, resulting in the calculation of physical damage for each affected exposure (fragility analysis); and 4) estimation of financial loss and downtime, also including equipment failure information (which can be assessed using existing empirical databases). These metrics can be easily computed given knowledge of the repair costs/repair times for different failure modes (or damage states) [13]. The final output of this approach consists of estimates of the probability of incurring various loss levels over the life of an asset, allowing the calculation of average annual loss of an OWT/OWF, or, alternatively, the estimation of total loss values corresponding to various recurrence intervals [14]. These are useful metrics that can be used to improve decision making, and are commonly used to assess insurance losses for various assets exposed to natural hazards [15].

Fragility functions quantify the probability of exceeding certain limit (or damage) states, LS [13], which can range from minor damage to complete structural collapse, as a function of various intensity levels of the considered hazard(s). Limit states are typically defined in terms of engineering demand parameters (EDPs), e.g. the stress in a component or hub displacement from structural analysis, which are used to assess the exceedance of EDP thresholds for each limit state of interest, i.e., EDPLS. The environmental conditions, the main source of variable loading on an OWT, are represented through intensity measures (IMs) considered to be 
representative of the wind and wave damage potential with respect to the specific structure. Fragility functions can be combined with a hazard model (in terms of the considered IM) to compute the mean annual rate of limit state exceedance, $\lambda_{L S}$, of the asset under investigation, as in Eq. (1) (e.g., [16]):

$$
\lambda_{L S}=\int_{i m} F_{L S}(x)\left|d \lambda_{I M}(x)\right|
$$

In Eq. (1), $F_{L S}(x)$ is the fragility function, i.e., $P\left[E D P>E D P_{L S} \mid I M=x\right] ; \lambda_{I M}(x)$ is the hazard curve in terms of IM (evaluated at $\mathrm{x}$ ), and $d \lambda_{I M}(x)$ denotes its differential with respect to IM (also evaluated at $\mathrm{x}$ ). In simplistic terms, $d \lambda_{I M}(x)$ is the (annual) probability of observing a given hazard intensity. Fragility functions can be combined with damage-to-loss (or consequence) models to further derive vulnerability functions, expressing the likelihood of various loss levels as a function of the IM. This study does not address the consequences of failure, which include complicated supply chain, market, and economic considerations.

Very few examples of such fragility/vulnerability functions exist for OWTs, and no established guidance currently exists for deriving them. In this context, analytical (or numerical) fragility functions generated from structural simulations represent the preferred option due to the lack of empirical damage/failure data from past events for OWT structural components. The analytical approach is common in earthquake engineering, where procedures for fragility derivation are well consolidated [17], and have been implemented for a wide range of civil engineering structures and infrastructure components.

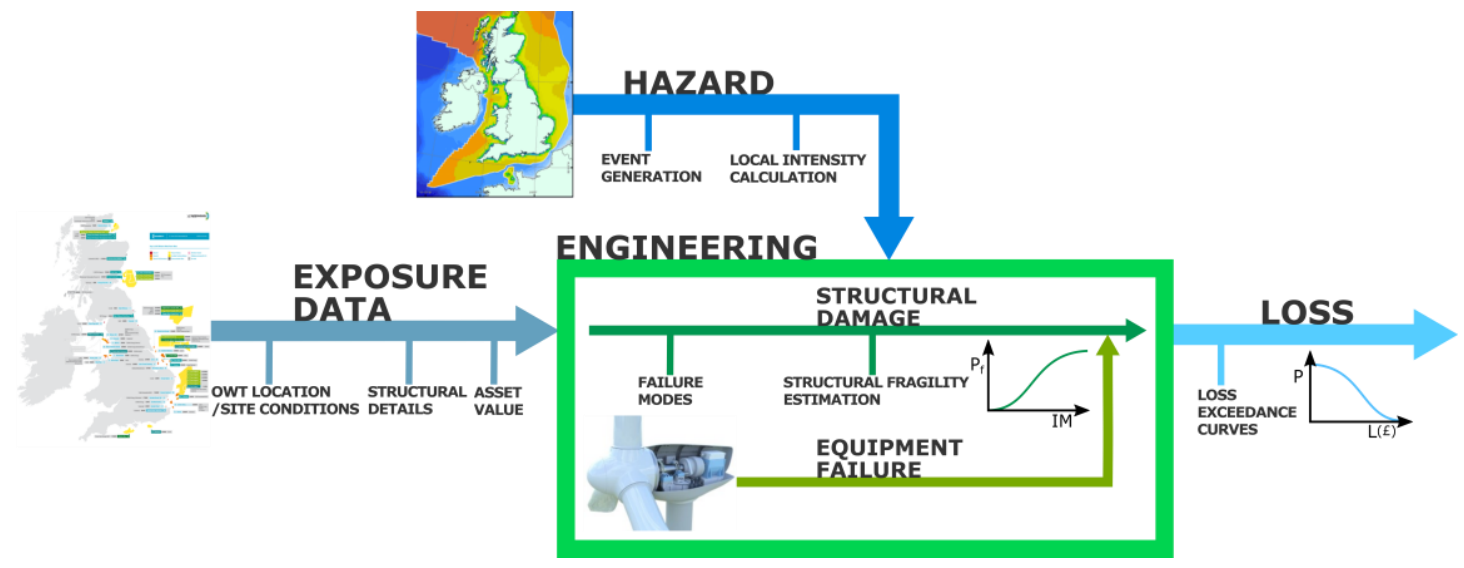

Figure 1: Probabilistic risk modelling framework adapted for application to an OWF.

In the field of wind energy, Sørensen and Toft [18] developed a procedure for assessing the ULS probability of failure of onshore turbine towers based on the first order reliability method (FORM). They also proposed a range of random variables capturing the uncertainty in modelling assumptions (together with that in load and material properties), as factors multiplying the computed demand and capacity values from structural simulation. An alternative approach, based on a simplified mechanical model, was developed by Quilligan et al. [19], also for onshore turbines, and was used to derive fragility functions. Their study considered uncertainties in material properties and loading, where random-variable models were used as direct inputs to the structural demand calculation. In their assessment, failure is assumed to occur after a plastic hinge forms in the tower. A comparison between the two approaches highlights that Sørensen and Toft included uncertainty in the capacity/load terms of the limit state after they had been evaluated using a (detailed) numerical model, whereas Quilligan et al. directly sampled inputs into the (simplified) numerical model (e.g. changing the 
tower thickness, effecting the stiffness and therefore deflection of the model). A similar approach for uncertainty quantification was applied by Muskulus and Schafhirt [20] for OWTs using a simplified structural model by decoupling the aero-elastic and structural analysis. The relatively small uncertainty in the structural geometry/capacity compared to the larger uncertainty in the demand calculation and the need to use coupled time-domain dynamic simulations to accurately predict these demands, seem to suggest that the approach used by Sørensen and Toft is generally preferable. Additionally, assessment of OWTs is more challenging because they are exposed to both wind and wave loading conditions. The fragility of OWTs was investigated by Wei et al. [21], who developed a performance-based assessment framework using nonlinear static analysis to calculate a response surface for the extreme response of the jacket-type support structure to different environmental conditions. Monte Carlo simulation was used to sample the material properties and calculate the probability of failure for hurricane-like events characterized by MRP as the IM (this aspect is further discussed below). Fragility functions were developed based on first yield and collapse limit states using base shear as an EDP. This was ultimately embedded within a full hurricane risk assessment procedure for farms located on the USA East Coast [10], similar to the probabilistic risk modelling approach proposed here. Fragility of OWTs on monopile foundations exposed to combined operational wind and wave conditions and earthquake hazard was investigated by Mardfekri et al. [22-25], including material, geometry and modelling uncertainties. De Risi et al. [26] also developed fragility functions for OWTs experiencing earthquakes occurring during normal operating conditions.

This brief literature review suggests the lack of a harmonized, practice-oriented procedure for deriving fragility functions for OWTs experiencing severe wind and wave conditions. In addition, there has been little research comparing the effect of different modelling and analysis assumptions on OWT fragility and assessing the impact that various random variable models, used to capture uncertainty affecting structural demand and capacity, have on the predicted failure probabilities.

This study aims to address the above gaps, proposing a coherent and practice-oriented framework for deriving fragility functions for the structural components of OWTs. It also investigates the sensitivity of fragility functions to different modelling and analysis choices through a case-study OWT. Specifically, this work focuses on OWTs supported on monopile substructures, as approximately $80 \%$ of currently installed OWTs have this type of foundation [27]. One complex, but potentially beneficial, feature of an OWT is that the wind loading is primarily transferred through the blades (although also acting on the tower). Failure of the blades before the tower or monopile would reduce the loading on these components, potentially preventing them from failing [5]. This effect is studied here by comparing fragility functions for the blades and the other structural components. Additionally, the extreme load calculation, the analytical definition of the limit state function, and the influence of including various sources of uncertainty in the analysis are discussed in detail. The case-study OWT is analysed at two different real-world OWF sites, through a comprehensive illustrative application to test the above issues.

The paper starts by introducing the two case-study sites, one in the North Sea and the other on the USA East Coast (Section 2). Next, the overall methodology for the fragility calculation is presented (Section 3), and the framework is implemented for each case-study site (Section 4). The results from this study are presented in Section 5 while Section 6 summarizes the main findings of the study. 


\section{Details of the case-study sites}

Two sites, both suitable for OWFs but experiencing contrasting environmental conditions, are investigated in this study. The first one is the Ijmuiden K13 site (referred to as Ijmuiden site in the rest of this paper) [28], located in the Dutch waters and exposed to extra-tropical cyclones; whereas the Massachusetts site [21] is located on the USA East Coast (at $40.5^{\circ} \mathrm{N} 69.3^{\circ} \mathrm{W}$ ), and is exposed to hurricanes. The first site has a water depth around $20 \mathrm{~m}$, making it a suitable location for the $20 \mathrm{~m}$ tall substructures used in this study. The Massachusetts site is deeper than $20 \mathrm{~m} \mathrm{[21];} \mathrm{however,} \mathrm{this} \mathrm{water-depth} \mathrm{value} \mathrm{is} \mathrm{assumed} \mathrm{here} \mathrm{to} \mathrm{provide} \mathrm{direct} \mathrm{comparisons}$ between the fragility functions derived for the same case-study structure under different environmental conditions and comparing results. It worth highlighting that, because of this latter assumption, the fragility functions resulting from this study may not be directly applicable to the Massachusetts case study; however, as discussed above, this paper aims to provide a general approach for fragility analysis, testing various modelling/analysis assumptions and discussing possible outcomes of the approach.

Ijmuiden has 22 years' worth of wind and wave measurements [28]. Statistical models representing the occurrence of different mean wind speeds and significant wave heights [29] have been developed for the site by applying linear regression with log correction to the recorded data [28]:

$$
\begin{gathered}
H_{s, 3 h r}=0.479 \ln (M R P)+6.063 \\
V_{h u b, 10 \min }=2.645 \ln (M R P)+31.695
\end{gathered}
$$

In Eq. (2), $H_{s, 3 h r}$ is the predicted three-hour significant wave height in meters, i.e., the average trough to crest height of the highest one-third waves [29]; $V_{\text {hub,10min }}$ is the 10-minutes hubheight mean wind speed in $\mathrm{m} / \mathrm{s}$ (10 minutes averaging is a common assumption based on observation that mean wind speed is approximately constant over this period of time).

At the offshore Massachusetts site, hurricane conditions were modelled by Wei et al. [21] by simulating a stochastic catalogue of 100,000 years of hurricane activity in the Atlantic Basin (100,000 years is a typical length of a stochastic catalogue to be used in probabilistic risk modelling for (re)insurance applications). Combining this catalogue with physical models such as the Holland and Young models to estimate the wind speed and wave height of each storm at a given site (local intensities), allows fitting Generalized Extreme Value (GEV) distributions to the hurricane generated wind speeds and wave heights. The value of the wind speed and wave height corresponding to a specified MRP can be extracted from the upper tail of the GEV distributions representing synthetic hurricane data.

$$
f(x \mid k, \sigma, \mu)=\frac{1}{\sigma}\left(1+k \frac{(x-\mu)}{\sigma}\right)^{-1 / k-1} \exp \left(-\left(1+k \frac{(x-\mu)}{\sigma}\right)^{-1 / k}\right)
$$

In Eq. (3), the model parameters are shape $(k)$, scale $(\sigma)$ and location $(\mu)$; these are defined for the Massachusetts site using the values in Table 1. The $x$ variable represents either the yearly maximum 10-minute mean wind speed or the significant wave height, depending on which set of parameters are used for the model fitting. These distributions were fit by Wei et al. [21], who predicted mean wind speeds using the Holland model and converted these from a $10 \mathrm{~m}$ elevation to hub height values using a correction factor of 1.289 ..

Table 1: GEV parameters for the Massachusetts site [21].

\begin{tabular}{cccc}
\hline Parameter & Shape $(\boldsymbol{k})$ & Scale $(\boldsymbol{\sigma})$ & Location $(\boldsymbol{\mu})$ \\
\hline \hline $\mathrm{V}_{\mathrm{w}}$ & 0.0915 & 6.2898 & 12.2264
\end{tabular}

Site-specific ULS Fragility of OWT on Monopile Substructures 
The environmental conditions associated with a set of different MRPs are plotted on Figure 2 (left); the MRP is a surrogate for the joint wind-wave IM in this study, as further discussed in Section 4.1. It is noted that the wind and wave conditions at large MRPs are evaluated by extrapolating a much shorter set of measured site conditions for the Ijmuiden site; therefore, specific numerical values (and their implications in terms of analysis results) should be interpreted with caution due to the extensive extrapolation. A more detailed approach based on physics-based event generation (as in the case of the Massachusetts site) may be more suitable to capture the expected values (and possible correlations) between wind and wave conditions, especially at rare MRPs [21].

MRPs for the Massachusetts site are selected to cover the mean wind speed range from $40 \mathrm{~m} / \mathrm{s}$ to $80 \mathrm{~m} / \mathrm{s}$. Very high MRPs at the Ijmuiden site are necessary to produce fragility functions that can capture failure modes of components, as discussed in Section 5. However, this does not affect the main conclusions of the study, which relate to the relative properties of the fragility functions derived for both sites and for different modelling/analysis assumptions. Also, these very high MRPs may have an important contribution to the total failure probability which is needed by decision makers regarding the risk profile of the structure and associated financing, underwriting, and regulatory issues.
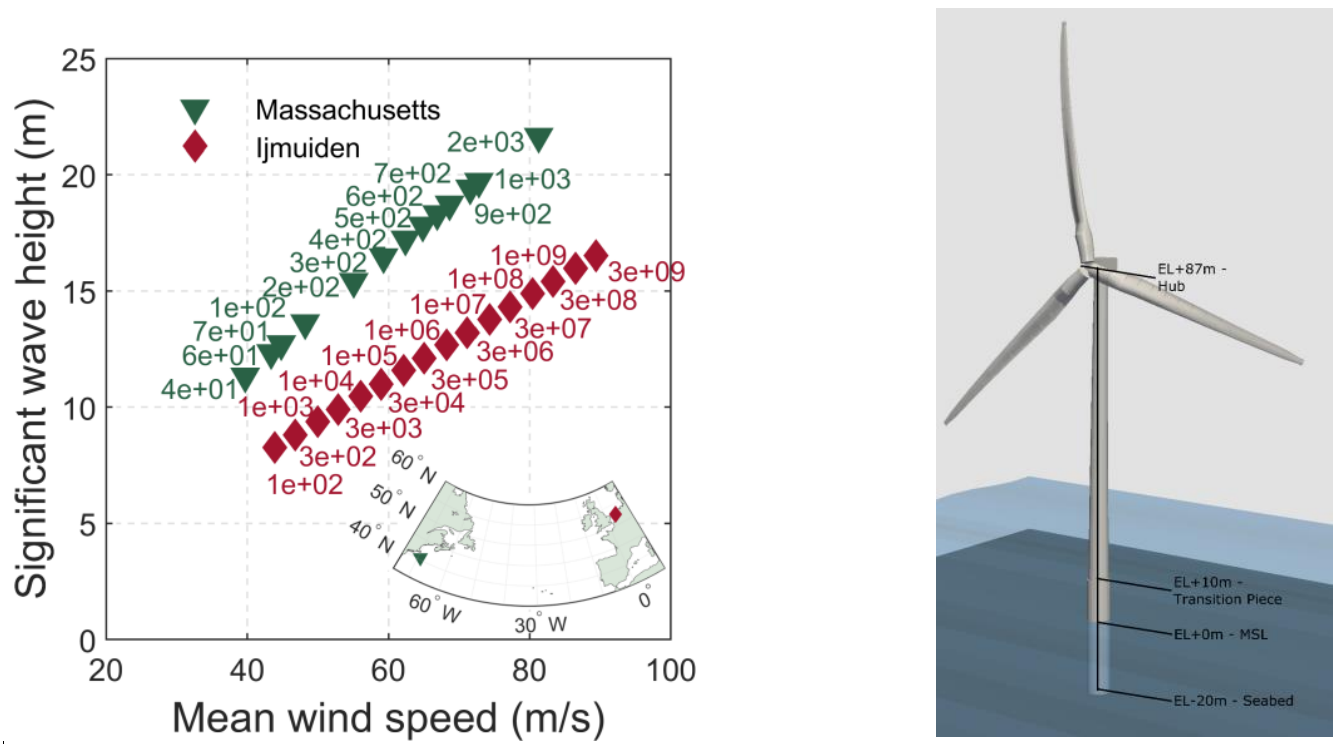

Figure 2: Comparison of wind and wave conditions at different MRPs for the Massachusetts and the Ijmuiden OWF sites (left); inset map shows site locations. OWT structural model in OpenFAST (right) with the main elevations highlighted in the figure.

\section{Fragility calculation methodology}

Analytical (or numerical) fragility functions are developed using a computational model to estimate structural response for various loading conditions rather than relying on empirical data. This approach is necessary as very scarce damage/failure data for OWTs is publicly available, and failure events are expected to be rare in any case.

The framework presented in Figure 1 requires a method for assessing wind- and wave-induced demands to the OWT structure. One applicable method is the Incremental Wind Wave Analysis (IWWA) proposed for OWTs by Wei et al. [30]. In this case, the OWT structural response is assessed at progressively severe environmental conditions, consisting of significant wave 
heights and mean wind speeds. However, the numerical model used to evaluate the structural response is associated with idealizations and introduces uncertainty into the prediction of the structural response. These effects are modelled as random variables, with a defined probability distribution, and need to be sampled at each environmental condition, i.e., corresponding to pairs of wind and wave conditions, for input to the numerical structural model. This results in a fragility calculation procedure that is very similar to the multi-stripe analysis method which is commonly used in earthquake engineering [31]. In IWWA, wind and wave conditions can be coupled using the MRP to save computational time, as a reduced set of conditions need to be analysed. The output is the structural response to increasingly rare environmental conditions at the site (characterized by a given MRP value). Due to the low stiffness of OWTs on monopiles in comparison to those on jackets, which were the focus of existing implementations of IWWA [21], and to explicitly capture the dynamic response to loads, IWWA combined with a coupled time-history analysis [32] is used here for OWTs on monopile substructures. The approach used here was initially proposed in [32].

The fragility calculation procedure is implemented through the six steps listed in the flowchart in Figure 3. These include:

1. Select a set of MRPs, with $N_{M R P}$ being the number of MRPs evaluated at a given site.

2. Calculate mean wind speed $\left(V_{w}\right)$ and significant wave height $\left(H_{S}\right)$ (from independent probability distributions) at a given MRP. The considered probability distributions should be developed for the OWF site-specific conditions.

3. Generate a Monte Carlo sample containing realizations of the environmental conditions (in terms of turbulent wind and wave time histories) and other random variables which influence the demand and capacity of the OWT (where $N_{\text {samples }}$ realizations of those random variables are generated at each MRP). This step is discussed in more depth in Section 4.5. Details on random variable models used in the illustrative applications are provided in Section 4.3. The total number of random variables is $N_{R-v a r}$.

4. Run structural analysis and evaluate the limit state equation(s) for each Monte Carlo sample at all MRP assessed; this employs a total of $N_{M R P} \cdot N_{\text {samples }}$ structural simulations.

5. Estimate the probability of failure at each MRP, as discussed in Section 4.5.

6. Fit a fragility function to the pairs of MRP and probabilities of failure calculated in step 5.

The details required to implement the fragility calculation are discussed in Section 4. This process allows a structural analysis package, such as OpenFAST (formally known as FAST), [33] to be used within the fragility calculation. It is also sufficiently general to encompass advanced structural reliability techniques; however, for the purpose of this study, only plain Monte Carlo simulation is applied. Misalignment between the wind and wave conditions would also have an important impact on structural loading. This was not modelled in the present study as, at high mean wind speeds (above $30 \mathrm{~m} / \mathrm{s}$ ) the misalignment was observed to reduce at the Ijmuiden site [28] and for the Massachusetts site this information was not available. 


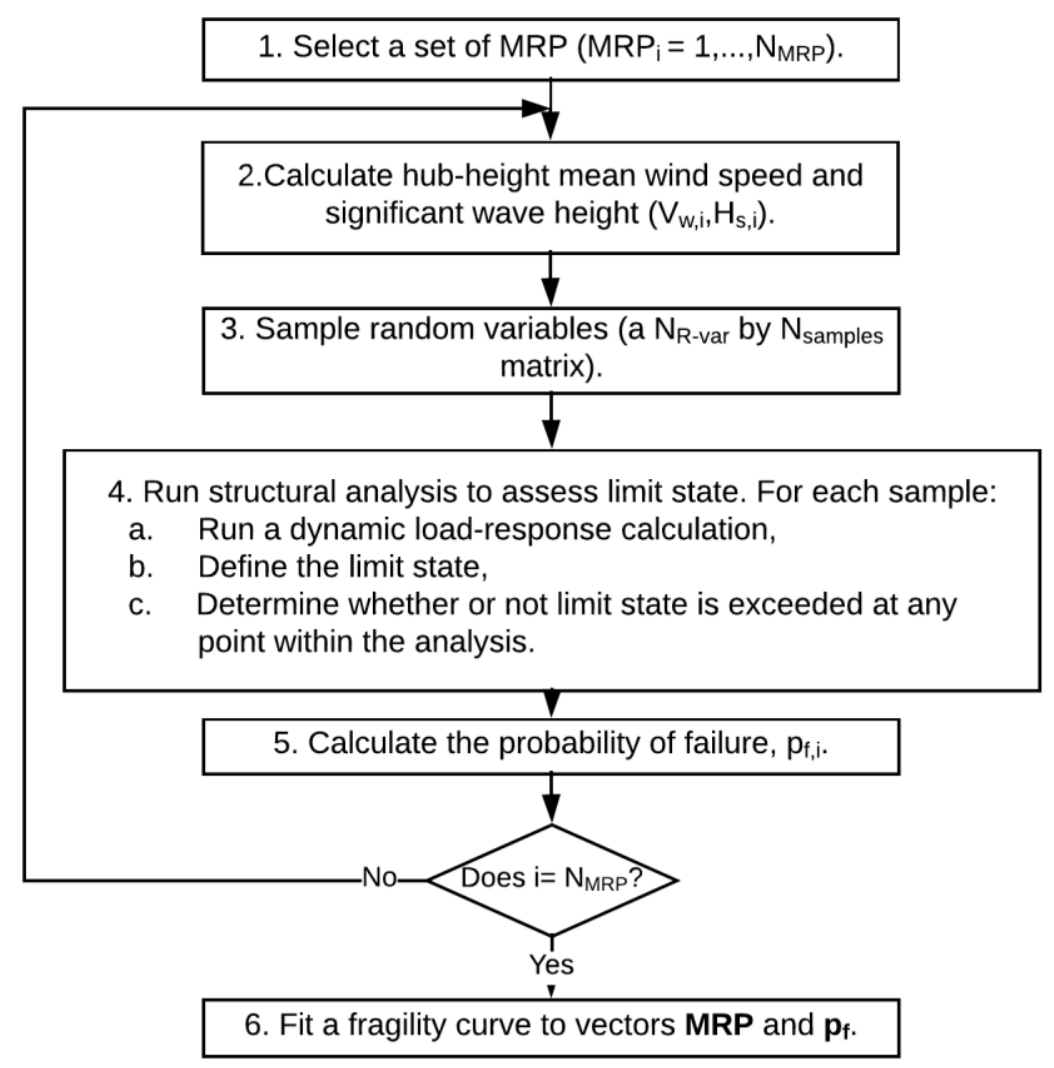

Figure 3: Flowchart describing the fragility calculation procedure.

\section{$4 \quad$ Implementation of the fragility framework}

\subsection{Hazard calculation}

The hazard intensity calculation is simplified in this paper by combining the wind and wave conditions into a scalar IM, the MRP, by using the distributions described in Section 2. This conservative approach has significant limitations due to the assumption that wind and wave conditions at equivalent, independently estimated MRPs occur simultaneously. However, using a scalar measure of the hazard intensity requires fewer simulations and less information about the environmental conditions.

In principle, a joint probability model should be used to calculate joint wind-wave conditions corresponding to a specific MRP; but doing so is challenging due to the relative paucity of data available for calibrating joint models. Also, it is not possible to define a single combination of wind and wave conditions for a specified MRP value. More generally, introducing the wind speed and wave height directly as IMs would require treatment of a vector-valued IM, a significant complication that, at this point in the development of a probabilistic risk modelling framework for OWTs, does not add significant value.

A set of 16 MRPs are assessed here, as listed in Table 2. The corresponding wind and wave values have been calculated using the distribution assumptions from Eq. (2) for Ijmuiden and Eq. (3) for Massachusetts. For this latter case, once the GEV distributions describe above have been fitted to the empirical wind and wave data, it is possible to extract tail values of the cumulative distribution function (CDF) corresponding to the target MRP. It is worth noting that at higher MRPs the wave conditions become more complicated - as waves start to break - 
and therefore the maximum MRP has been limited to a value smaller than the one causing structural failure in some cases

Table 2: MRP, in years, and corresponding environmental conditions at Massachusetts (MA) and Ijmuiden (IJ) wind farm sites.

\begin{tabular}{|c|c|c|c|c|c|c|c|c|c|c|c|c|c|c|c|c|}
\hline IJ MRP & $1 \times 10^{2}$ & $2 \times 10^{3}$ & $31 \times 10^{3}$ & $3 \times 10^{3}$ & $1 \times 10^{4} 3$ & $3 \times 10^{4}$ & $1 \times 10^{5}$ & $3 \times 10^{5}$ & $51 \times 10^{6}$ & $3 \times 10^{6}$ & $61 \times 10^{7}$ & $3 \times 10^{7} 1$ & $1 \times 10^{8} 3$ & $3 \times 10^{8}$ & $1 \times 10^{9}$ & $3 \times 10^{9}$ \\
\hline MA MRP & $4 \times 10$ & $6 \times 10$ & $7 \times 101$ & $1.5 \times 10^{2} 1$ & $21.5 \times 10^{2} 2$ & $2 \times 10^{2}$ & $2.5 \times 10^{2}$ & $23 \times 10^{2}$ & $24 \times 10^{2}$ & $5 \times 10^{2}$ & $26 \times 10^{2}$ & $7 \times 10^{2} 9$ & $9 \times 10^{2} 1$ & $1 \times 10^{3} 1$ & $.5 \times 10^{3}$ & $2 \times 10^{3}$ \\
\hline $\mathbf{I J} V_{w}(\mathrm{~m} / \mathrm{s})$ & 44 & 47 & 50 & 53 & 56 & 59 & 62 & 65 & 68 & 71 & 74 & 77 & 80 & 83 & 86 & 89 \\
\hline $\mathbf{I J} \boldsymbol{H}_{\boldsymbol{s}}(\mathbf{m})$ & 8 & 9 & 9 & 10 & 10 & 11 & 12 & 12 & 13 & 13 & 14 & 14 & 15 & 15 & 16 & 17 \\
\hline MA $V_{w}(\mathbf{m} / \mathbf{s})$ & 40 & 43 & 45 & 48 & 51 & 53 & 56 & 59 & 61 & 64 & 67 & 69 & 72 & 75 & 77 & 80 \\
\hline MA $\boldsymbol{H}_{\boldsymbol{s}}(\mathbf{m})$ & 11 & 12 & 13 & 14 & 14 & 15 & 16 & 16 & 17 & 18 & 18 & 19 & 20 & 20 & 21 & 21 \\
\hline
\end{tabular}

\subsection{OWT structural model}

\subsubsection{Environmental load}

The sea state is modelled as a random process by using a wave spectrum, representing the frequency content of the waves. The assumed spectrum is the JONSWAP [29] and a waveheight time history is then generated by using the inverse Fourier transform. The spectrum requires the significant wave height, which determines the energy content, and a peak factor (which determines how peaked the spectrum is [29]) calculated using the recommended method in IEC 61400-3 Annex B [6]. The peak spectral period ( $\left.T_{p}\right)$, i.e., the wave period at which the wave spectrum has a maximum [29], is also necessary and determines the frequency at which the spectral peak occurs. This value was defined deterministically at both sites; Myers et al. [34] evaluate the range of $T_{p}$ values necessary to meet the conditions specified by IEC-614003 as indicated by Eq. (4). In this work, only the lower bound value is conservatively used since it generates the largest loads, making the wave spectrum closest to the natural frequency of the considered OWT.

$$
11.7 \sqrt{H_{s} / g} \leq T_{p} \leq 17.2 \sqrt{H_{s} / g}
$$

From the wave-height time history, the kinematics of individual water particles distributed along the monopile are calculated using the $2^{\text {nd }}$ order wave model developed by Agarwal and Manual [35]. This time series is converted into structural loads using Morrison's equation, implemented in the software package HydroDyn [36]. The study does not account for additional loads due to current or changes in mean water level.

The turbulent wind acting on the OWT is continuous but is commonly evaluated numerically at discrete points on a grid overlying the structure. The turbulent wind time histories are evaluated using the software package Turbsim [37], which converts a Kaimal spectrum with turbulence type ' $\mathrm{B}$ ' [6] into a wind time history using inverse Fourier transforms at each grid point. The correlation between the wind speed at different point is captured using an exponential coherence model as recommended in IEC 61400-1 [38]. Wind shear, changing mean wind speed with elevation, was include using a power-law profile with exponent 0.14 [6].

\subsubsection{Global structural analysis}

The OWT considered in this study is based on the National Renewable Energy Laboratory (NREL) 5MW reference turbine [39] with a monopile foundation, as shown in Figure 2 (right) and with main properties listed in Table 3 . The hub is supported by the tower and is located at Elevation (EL) $+87.6 \mathrm{~m}$ above the Mean Sea Level (MSL). It is attached to a $126 \mathrm{~m}$ diameter 3- 
bladed rotor, where the blades are labelled as blade \#1, \#2 or \#3. The hub can rotate around the central axis of the tower, where any discrepancy in the perpendicular angle between the wind flow and plane in which the blades rotate is referred to as yaw error [40]. The blades rotate about a horizontal axis running through the centre of the rotor plane; the blade position is described by the azimuth angle: when azimuth is $0^{\circ}$, blade \#1 points directly upwards; as the azimuth angle increases, blade \#1 rotates clock-wise about the rotor-axis if observed while facing downwind. The monopile support structure spans from EL $+10 \mathrm{~m}$ to the mudline at EL $20 \mathrm{~m}$. At the base of the tower, a transition piece connects the tower and monopile. A full list of dimensions and material properties of the turbine structure are provided by Jonkman et al. [39]. The dimensions of the material properties and the geometry of the NREL 5MW blades are provided by Resor [41]. Finally, the dimensions of the transition piece used in this study are taken from Lee et al. [42]; these did not impact the global analysis but are used to evaluate the failure limit states.

Table 3: Main dimensions for the NREL 5MW case-study OWT.

\begin{tabular}{ll}
\hline \hline Parameter & Value \\
\hline Mass of the rotor-nacelle assembly $(\mathrm{kg})$ & 350,000 \\
Tower diameter bottom, top $(\mathrm{m})$ & $6,3.87$ \\
Tower wall thickness bottom, top (mm) & 35,25 \\
Monopile diameter (m) & 6 \\
Monopile wall thickness (mm) & 60 \\
\hline
\end{tabular}

The NREL 5MW turbine has a cut-off speed $25 \mathrm{~m} / \mathrm{s}$ : when this mean wind speed is exceeded, the rotor enters its parked state by pitching the blades into the wind to prevent damage. In all the considered analysis, the mean wind speed was well-above the cut-off.

The foundation is modelled using an apparent fixity (AF) model, which represents foundation flexibility by extending the monopile below the mudline. The extension length is chosen to match the natural frequency from a spectral analysis where the monopile is embedded in a linear-elastic soil matrix. This assumes an embedded pile length of 30m [43], using soil properties in [44]. Dynamic response of the structure was calculated using the aeroelastic computer-aided engineering OpenFAST [33] to run sets of dynamic time-history analyses. The analysis length is 11 minutes, allowing the first minute to be cut (which includes transience) while leaving the full recommended analysis length with the first minute cut out.

\subsubsection{Model limitations}

The assumptions used in this study introduce a number of simplifications into the load-response calculation, primarily: the simplified foundation model is linear but the soil behaves nonlinearly at high loads [43]. Additionally, the aero-elastic code OpenFAST is based on small deflections and is not as accurate as non-linear aeroelastic methodologies [45] in capturing extreme and transient loading. Additionally, the second order wave model cannot capture the loads caused by large or breaking storm waves. As discussed above, the aim of this paper is to compare the relative features of the fragility functions dependent on different modelling/analysis assumptions, particularly in terms of uncertainty characterisation. Therefore, the use of a simplified analysis was judged sufficient for the purpose of this study. The NREL 5MW OWT was not designed specifically for either site used in this study, therefore the fragility values should not be expected to match those derived for an OWT design based on the site hazard conditions such as those derived by Hallowell et al. [10].

Site-specific ULS Fragility of OWT on Monopile Substructures 


\subsection{Random variables considered in the study}

The uncertainty introduced by using numerical models to estimate the response of the casestudy OWT are captured by defining the random variables shown in Table 4 and used in Eq. (5) to Eq. (9). For each random variable, Table 4 provides the random variable model and its parameters, e.g., the mean value and the coefficient of variation $(\mathrm{CoV})$, i.e., the ratio of the standard deviation to the mean. The list includes variables associated with the models and materials. The distribution types and their moments are taken from published data, as indicated in Table 4; although not explicitly discussed in each considered reference, these assumptions are based on either engineering judgement or calibration to empirical data. Most take the form of multiplicative factors that are used to scale either the nominal (i.e., from structural analysis) demand or capacity term in the limit state, Eq. (5) to Eq. (9), and are indicated by $X$. in Table 4. Other random variables relate to uncertainty in the material properties.

As discussed above, the simulation assumes that the wind turbine is parked; the initial azimuth angle of the rotor will therefore influence the loading on the blades, as the wind profile is not constant. However, it is not known what position the rotor will stop in, so azimuth is modelled as a random variable with a uniform distribution between $0^{\circ}$ and $180^{\circ}$ (an upper limit of $120^{\circ}$ could also be used due to symmetry of the rotor). Additionally, misalignment between the incoming wind flow and the turbine rotor will impact loading. IEC recommends assessing up to $15^{\circ}$ yaw error; the recent study of Morato et al. [40] assessed $8^{\circ}$ yaw misalignment. However, no data was available to determine a distribution; in its absence, a uniform distribution was assumed based on engineering judgment with limits $-8^{\circ}$ to $8^{\circ}$ following Morato et al. [40]. The environmental load models utilize inverse Fourier transforms to convert stationary frequency spectra into random time signals. In this context, the random variable is the random seed used to generate phase angles used in the transform. Unlike the multiplicative factors, these random variables directly impact the structural calculation and are inputs to OpenFAST.

Table 4: Random variables models and parameters. The distribution parameters for parameters with a uniform random variable distribution, in square brackets, are the upper and lower limits.

\begin{tabular}{|c|c|c|c|c|c|}
\hline Type & Parameter & Mean & CoV & Distribution & Ref \\
\hline \multirow{6}{*}{$\begin{array}{l}\text { Model } \\
\text { uncertainty }\end{array}$} & Structural dynamics $\left(X_{d y n}\right)$ & 1 & 0.05 & Lognormal & [46] \\
\hline & Simulation statistics $\left(X_{\text {sim }}\right)$ & 1 & 0.10 & Normal & [18] \\
\hline & Stress evaluation $\left(X_{s t r}\right)$ & 1 & 0.03 & Lognormal & [18] \\
\hline & Blade model uncertainty $\left(X_{\delta l}\right)$ & 1 & 0.05 & Lognormal & [18] \\
\hline & Critical load capacity $\left(X_{c r}\right)$ & 1 & 0.10 & Lognormal & [18] \\
\hline & $\begin{array}{l}\text { Material model uncertainty } \\
\left(X_{m a t}\right)\end{array}$ & 1 & 0.05 & Lognormal & [18] \\
\hline \multirow{3}{*}{ Material } & Steel yield strength, $\mathrm{MPa}\left(F_{y}\right)$ & 240 & 0.05 & Lognormal & [18] \\
\hline & $\begin{array}{l}\text { Steel Young's modulus, MPa } \\
(E)\end{array}$ & $2 \times 10^{5}$ & 0.02 & Lognormal & [18] \\
\hline & $\begin{array}{l}\text { Concrete tensile strength } \\
\left(X_{\text {con }}\right)\end{array}$ & 1 & 0.3 & Lognormal & [47] \\
\hline \multirow{2}{*}{ Rotor } & Blade 1 azimuth angle $\left(X_{a z}\right)^{*}$ & \multirow{2}{*}{\multicolumn{2}{|c|}{$\begin{array}{l}{\left[\begin{array}{ll}0^{\circ} & 180^{\circ}\end{array}\right]} \\
{\left[\begin{array}{ll}-8^{\circ} & 8^{\circ}\end{array}\right]}\end{array}$}} & Uniform & \\
\hline & Yaw angle $\left(X_{\text {yaw }}\right)$ & & & Uniform & \\
\hline \multirow{2}{*}{$\begin{array}{l}\text { Environme } \\
\quad \text { ntal }\end{array}$} & Wind phase angle $\left(X_{\text {seed,wi }}\right)$ & \multicolumn{2}{|c|}{$\left[\begin{array}{ll}0 & 1\end{array}\right]$} & Uniform & \\
\hline & Wave phase angle $\left(X_{\text {seed }, \text { wa }}\right)$ & \multicolumn{2}{|c|}{$\left[\begin{array}{ll}0 & 1\end{array}\right]$} & Uniform & \\
\hline
\end{tabular}

*Note - an azimuth of $0^{\circ}$ indicates that blade \#1 is pointing directly upwards. 


\subsection{Limit state definition}

A limit state defines the conditions beyond which a structural component no longer satisfies one of its performance objectives. The focus of this work is on ULS failure of the OWT structural components, and to this end, failure of the tower, monopile, blades, or transition piece are assessed. Failure in the ULS relates to exceedance of the maximum load carrying resistance [7]. These criteria are evaluated for the different OWT structural components independently, as described in the following sections. Failure is assumed to occur at the first exceedance of the structural capacity by the demand in a given time-history analysis, i.e., making the problem time-independent.

\subsubsection{Monopile and tower}

Collapse of the monopile or tower is assessed using two different limit state models. The first is taken from the work of Sørensen et al. [18] where failure occurs when the maximum moment in the tower exceeds the cross-section plastic moment reduced by a factor calculated from the cross-sectional properties. The factor represents a linear fit to the Eurocode 3 buckling limit state [48] for a shell with normal quality fabrication tolerance (class C), and may result in moments in excess of yielding in the outer fibre of the cross-section:

$$
\begin{gathered}
G_{M_{c r}}=\frac{1}{6}\left(1-0.84 \frac{D}{t} \frac{F_{y}}{E}\right)\left(D^{3}-(D-2 t)^{3}\right) X_{\text {mat }} X_{c r} F_{y}- \\
M_{U L T}\left(X_{a z}, X_{\text {yaw }}, X_{\text {seed }}\right) X_{\text {dyn }} X_{\text {sim }} X_{\text {str }}
\end{gathered}
$$

This will be referred to as the $M_{c r}$ limit state for the remainder of the paper; $M_{U L T}\left(X_{a z}, X_{\text {yaw }}, X_{\text {seed }}\right)$ is the considered EDP and is defined as the maximum bending moment in each structural simulation. The $X$ terms are variables which capture modelling uncertainty and are defined on Table 4 . In Eq. (5), $D$ is the component diameter (m), $t$ is the thickness $(\mathrm{m})$ and $F_{y}$ is the yield stress $\left(\mathrm{N} / \mathrm{m}^{2}\right)$. For brevity the wind and wave seed variables have been combined into a single parameter $\left(X_{\text {seed }}\right)$.

The NREL 5MW is a large utility scale OWT, both the monopile and tower have a low thickness to diameter ratio and are non-compact according to the definition provided in DNVOS-J101 Section 7.3.1 [49]. Additionally, they exceed the Eurocode Class 3 cross-section limits [50], indicating shell behaviour. As a result, the DNV steel buckling code [51] is used as the second limit state model, which uses von Mises stress as the EDP. The monopile buckling resistance, $f_{c a p, M}\left(F_{y}, \sigma_{V M . M}\right)$, is calculated using the provisions for local shell buckling in Section 3.4 of DNV-RP-C202 [51].

The column buckling check is only necessary in the case that a combination of the shell geometrical properties is larger than 2.5 times the ratio of the Young's Modulus to the yield stress:

$$
\left(\frac{k L_{c}}{i_{c}}\right)^{2} \geq 2.5 \frac{E}{f_{y}}
$$

In Eq. (6), $k$ is the effective length defined by the code (2.1 for a cantilever beam [51]), $L_{c}$ is the cylinder length and $i_{c}$ is the radius of gyration. This limit was not violated for the monopile as it is assumed to be fixed at the mudline, reducing the unconstrained length to the water depth. However, the tower does exceed this ratio, so the buckling resistance, $f_{c a p, T}\left(F_{y}, \sigma_{V M . T}\right)$, is calculated including the provisions for column buckling in Section 3.8 of DNV-RP-C202 [51]. These were found to be the most onerous provisions. Capacity in both formulations is time- 
variant because the buckling strength is dependent on the stress state within the component; however, it is demonstrated later in the paper, that this variability is small. Structural demand is calculated by transforming the force and moment outputs from OpenFAST at each time step into stresses using a membrane shell calculation [51]. The DNV limit state is also considered for both the tower $(T)$ and monopile $(M)$, Eq. (7):

$$
\begin{aligned}
G_{D N V, T} & =f_{\text {cap }, T}\left(X_{\text {mat }} F_{y}, \sigma_{V M . T}\right) X_{c r}-\sigma_{V M . T}\left(X_{a z}, X_{y a w}, X_{\text {seed }}\right) X_{d y n} X_{s i m} X_{s t r} \\
G_{D N V, M} & =f_{c a p, M}\left(X_{\text {mat }} F_{y}, \sigma_{V M . M}\right) X_{c r}-\sigma_{V M . M}\left(X_{a z}, X_{y a w}, X_{\text {seed }}\right) X_{\text {dyn }} X_{\text {sim }} X_{s t r}
\end{aligned}
$$

The variables are the limit state function $\left(G_{D N V, T}\right.$ and $\left.G_{D N V, M}\right)$, tower von Mises stress at each time step $\left(\sigma_{V M . T}\right)$, and monopile von Mises stress at each time step $\left(\sigma_{V M . M}\right)$.

It should be noted that the monopile limit state is evaluated at the mudline only, as the shell is uniformly thick, and the largest moment occur at this location. The tower code check is conducted along the height of the tower as the cross-section is tapered.

\subsubsection{Transition piece}

A grouted connection is used to join the monopile to the transition piece. This transfers all the horizontal and vertical loads acting on the tower/rotor into the monopile. Failure of the grout occurs at the interface between the grout and pile or transition piece; this may result in the transition piece slipping relative to the monopile [52]. An analytical calculation for assessing grouted connections is provided by DNVGL-ST-0126 [7]. The maximum grout tensile capacity $\left(f_{T P}\right)$ can be calculated through the provision in Section 4.5.1.13 of DNVGL-ST-C502 [53]. The maximum tensile stress demand $\left(\sigma_{T P}\right)$ can be calculated using the analytical equations in DNVGL-ST-0126 [7] Appendix C.1 the background to which is provided by Lotsberg [52] (including experimental validation):

$$
G_{T P}=f_{T P} X_{c o n}-\sigma_{T P}\left(X_{a z}, X_{y a w}, X_{\text {seed }}\right) X_{d y n} X_{\text {sim }} X_{s t r}
$$

A tapered transition piece with no shear keys is assumed and as discussed in Section 4.2.2 the structural properties were taken from Lee et al. [42].

\subsection{3 $\quad$ Blades}

The blades convert wind flow into structural loading and therefore failure of a blade would reduce loads experienced by the other structural components. This has been observed in the failure of onshore wind turbines which have experienced typhoon winds [5]. Hence, the fragility of these components is noteworthy as it may also impact the failure of the other structural components. However, the blades are complex structures and are usually made from composite materials. Detailed finite element analysis (FEA) models are typically used to assess failure of the blades [54]. In lieu of this a simplified limit state based on maximum blade root flapwise moment is used. The limit state is defined as the blade flapwise moment capacity $\left(M_{c a p}\right)$ minus the blade flapwise moment demand $\left(M_{d e m}\right)$ :

$$
G_{b l d}=M_{c a p}-M_{d e m}\left(X_{a z}, X_{y a w}, X_{\text {seed }}\right) X_{d y n} X_{\delta l} X_{s t r}
$$

The flapwise moment capacity is taken as $15,310 \mathrm{kNm}$ and was calculated by Resor [41] using a detailed FEA analysis for the NREL 5MW OWT blades. The moment demand is directly output from OpenFAST for each blade. 


\subsection{Implementation of the fragility calculation}

A total of 400 10-minute time-history simulations with different seeds and random variable samples are run for each MRP values on Table 2 at each site. The number of simulation (i.e., 400 ) is selected so that a probability of failure of $50 \%$ could be predicted with a CoV of 0.05 . In a separate study [55], the full probabilistic risk framework has been implemented utilizing the fragility curves developed here and assessing the number of random seeds required for the fragility curves, explicitly quantifying the error due to limited sampling using resampling.

The proposed approach results in a series of limit state evaluations at a discrete number of MRPs. The probability of failure for each OWT component at different MRPs can be estimated using the relevant limit state function (where $G$ refers a limit state $G_{M c r}, G_{D N V, T}$, etc). By using plain Monte Carlo simulation, an estimate of the probability of failure is simply the mean value of an indicator function $I(G \leq 0)$ which takes a value one when the relevant limit state function associated with one analysis run is negative (i.e. the structure fails during that simulation):

$$
p_{f}\left(M R P_{i}\right)=P\left[G_{i}<0 \mid M R P_{i}\right]=\frac{1}{N_{\text {samples }}} \sum_{k=1}^{N_{\text {samples }}} I\left(G_{i, k} \leq 0\right)
$$

In Eq. (10), $p_{f}\left(M R P_{i}\right)$ is the probability of failure at discrete samples of the MRP indexed by $i$ and $N_{\text {samples }}$ is the number of samples, 400 in this case.

A continuous fragility functions $\left(p_{f}(M R P)\right)$ is then fit to the discrete sampled data, assuming that a lognormal CDF can represent the probability of failure samples calculated using Eq. (10). This model, commonly used in the field of earthquake engineering, is a suitable parametric model for several civil engineering structures/applications $[13,56]$. This lognormal assumption is confirmed through a Chi-Square Goodness-of-Fit Test [57], with results only reported when the hypothesis test failed.

The fragility fitting provides the location $(\hat{\eta})$ and standard deviation parameters $(\hat{\beta})$ of the fragility function from which estimates of the probability of failure are evaluated, conditional on the $\mathrm{IM}\left(p_{f}(M R P)\right)$ :

$$
\hat{p}_{f}(M R P) \sim \Phi(\hat{\eta}, \hat{\beta}, M R P)
$$

The sets of MRP and corresponding probability of failures provide sample data; the fragility function parameters are selected using maximum likelihood estimation [58]. Specifically, the lognormal CDF is fitted using a two-step procedure: 1) the method of least squares is used to provide an initial estimate of the fragility function parameters; then 2) the maximum likelihood method is applied to refine the parameter estimation, where the samples are assumed to be binomially distributed, and the optimal fragility function parameters maximize the product of the binomial probability mass function (PMF) at each of the $N_{M R P}$ MRP samples:

$$
\operatorname{Likelihood}(\hat{\eta}, \hat{\beta})=\prod_{i=1}^{N_{M R P}}\left(\begin{array}{c}
N_{\text {samples }} \\
n_{i}
\end{array}\right) \hat{p}_{f}\left(M R P_{i}\right)^{n_{i}}\left(1-\hat{p}_{f}\left(M R P_{i}\right)\right)^{N_{\text {samples }}-n_{i}}
$$

where $\hat{p}_{f}\left(M R P_{i}\right)$ is the estimated probability of failure at a given MRP using the estimated lognormal distribution parameters, $N_{\text {samples }}$ is the number of analyses (i.e., 400$)$ and $n_{i}$ is the number of observed failures. This two-step approach is necessary because the MRP samples where all seeds fail (or survive) have narrow binomial mass functions. If the initial parameter

Site-specific ULS Fragility of OWT on Monopile Substructures 
estimates are not in the approximate region of the maximum likelihood solution, the logarithm of likelihood equation becomes numerically unstable.

The fragility function derivation is run in batches, with five different random variable configurations:

- $\mathrm{X} 1$ - Only randomness in the wind and wave time-histories (i.e. the random variables labelled as 'Environmental' in Table 4) is considered; all other variables are modelled as deterministic using their corresponding mean values;

- $\mathrm{X} 2$ - Same as X1 but also considering modelling and material random variables, and not rotor-related random variables;

- X3 - All random variables modelled explicitly;

- $\mathrm{X} 4$ - Same as X1 but also considering rotor-related random variables, comprising the azimuth and yaw angle;

- $\mathrm{X} 5$ - Same as X1 but also considering the azimuth random variable.

The full fragility analyses are run three times, because adding the rotor random variables required rerunning the structural analysis model, resulting in a total of 19,200 time-domain simulations for each site. This is necessary because the $\mathrm{X} 1 / \mathrm{X} 2$ random variable configurations assume a fixed azimuth and yaw angle whereas the $\mathrm{X} 3 / \mathrm{X} 4 / \mathrm{X} 5$ random variable configurations require yaw and or azimuth angle to be modelled as random variables.

\section{$5 \quad$ Results and discussion}

\subsection{Influence of yaw and azimuth}

An OWT enters its parked state at high wind speeds and the rotor stops rotating; however, it is not known at which angle relative to the vertical position (for blade \#1) the rotor will stop. Different rotor positions lead to different load patterns depending on whether a blade is pointing upwards (with increasing load along the length of the blade) or downwards (decreasing load along the length of the blade) due to wind shear [29]. Additionally, there is the possibility of an error in the yaw mechanism, meaning that the control system will not be able to maintain a perpendicular angle between the plane in which the blades rotate and the direction of wind flow as it changes. Both these effects have not been considered in existing wind turbine fragility studies, but have been observed to impact ULS loading [40]. Additional analyses were run to evaluate the how the fore-aft bending moment at the tower base, mudline and blade root varies with these properties. The range of azimuth and yaw angles $\left[-8^{\circ} 8^{\circ}\right]$ were split into a discrete series and a set of 10-minute simulations repeated for 10 random seeds at each. The resulting changing loads are shown in Figure 4 (azimuth) and Figure 5 (yaw) and are used to help explaining the fragility results.

Figure 6 (left) shows the impact of modelling the azimuth angle as a random variable, using the X5 random variable configuration, on the resulting fragility functions. For example, comparing the X1 and X5 random variable configuration for the monopile at the Ijmuiden site and using the DNV limit state leads to an unchanged location parameter and small reduction in standard deviation (from 1.88 to 1.83 , a $3 \%$ reduction). The cause of this is investigated in Figure 4, where the mudline and tower base moment are shown. A trend is visible whereby the moment is lowest when the rotor is in a position where one blade is pointing directly downwards (i.e., when blade 1 is at $60^{\circ}, 180^{\circ}$ and $300^{\circ}$ from the vertical). The changing azimuth angle has a small impact on the coefficient of variation in loading which is $1.65 \%$ and $2.11 \%$ for the monopile and tower respectively, especially when compared to the $\sim 1 \%$ caused by seed variability (shown the grey dots in Figure 4). This explains the small influence this parameter has on the fragility function. Azimuth angle has a larger impact on the blade loads, as shown in 
Figure 4 (bottom); only the results for blade 1 are presented for brevity (as the others followed the same trend with a $120^{\circ}$ angle shift). A fixed azimuth means that each blade has the same load pattern for all seeds, whereas when azimuth is modelled as a random variable the load pattern changes. The loading will increase or decrease along the blade depending whether it is angled upwards or downwards relative to the hub. Therefore, over a sufficiently large random sample of the azimuth angle, all blades experience approximately the same load pattern, because the azimuth angle is assumed uniformly distributed. As a result, the fragility functions for each blade in the X5 random variable configuration overlap, unlike the X1 fragility functions, Figure 6 (right). It is noted that blade \#2 was not observed to fail under the X1 conditions. In this case a single fragility function could be used for the blades (i.e. which aggregates the individual results) whereas in the case where a single deterministic azimuth is used, blade \#1 and blade \#2 and \#3 have a distinct behaviour, see Figure 6 (right).

A similar deviation to the changing load with azimuth angle is observed for the yaw error variable in the tower and monopile components, Figure 5. However, a continuous trend of increasing load with increasing yaw error is visible. The variation in loading only causes a small change in the tower and monopile fragility functions, see Figure 6 (left) for the X4 random variable configuration, e.g. for the monopile, the location parameter is constant and the standard deviation reduces (from 1.88 to $1.71, \sim 10 \%$ ) compared to the $\mathrm{X} 1$ random variable configuration. However the limits on yaw error were enforced here by applying the values from Morato et al. [40], and it is expected that, if a larger range of yaw error is used, the impact on the fragility function would be greater. In contrast, a noticeable impact is observed on the blade fragility; this is again a result of the large impact yaw has on the blade root moment, Figure 5 (bottom). For blades, inclusion of azimuth and yaw error increases the variation of the fragility function substantially in comparison to the case where neither is modelled (X1 random variable configuration) and this effect can be seen clearly by comparing the fragility functions for the $\mathrm{X} 1, \mathrm{X} 4$ and X5 random variables configurations in Figure 6 (right). These results also suggest that the assumption of lognormal model is not suitable for the blades when azimuth and yaw are modelled as random variables. This was confirmed by the results of the Chi-Square goodness-of-fit test which returned $p$-values lower than the 0.05 significance threshold. In the remainder of this paper they will be represented using an empirical CDF. 

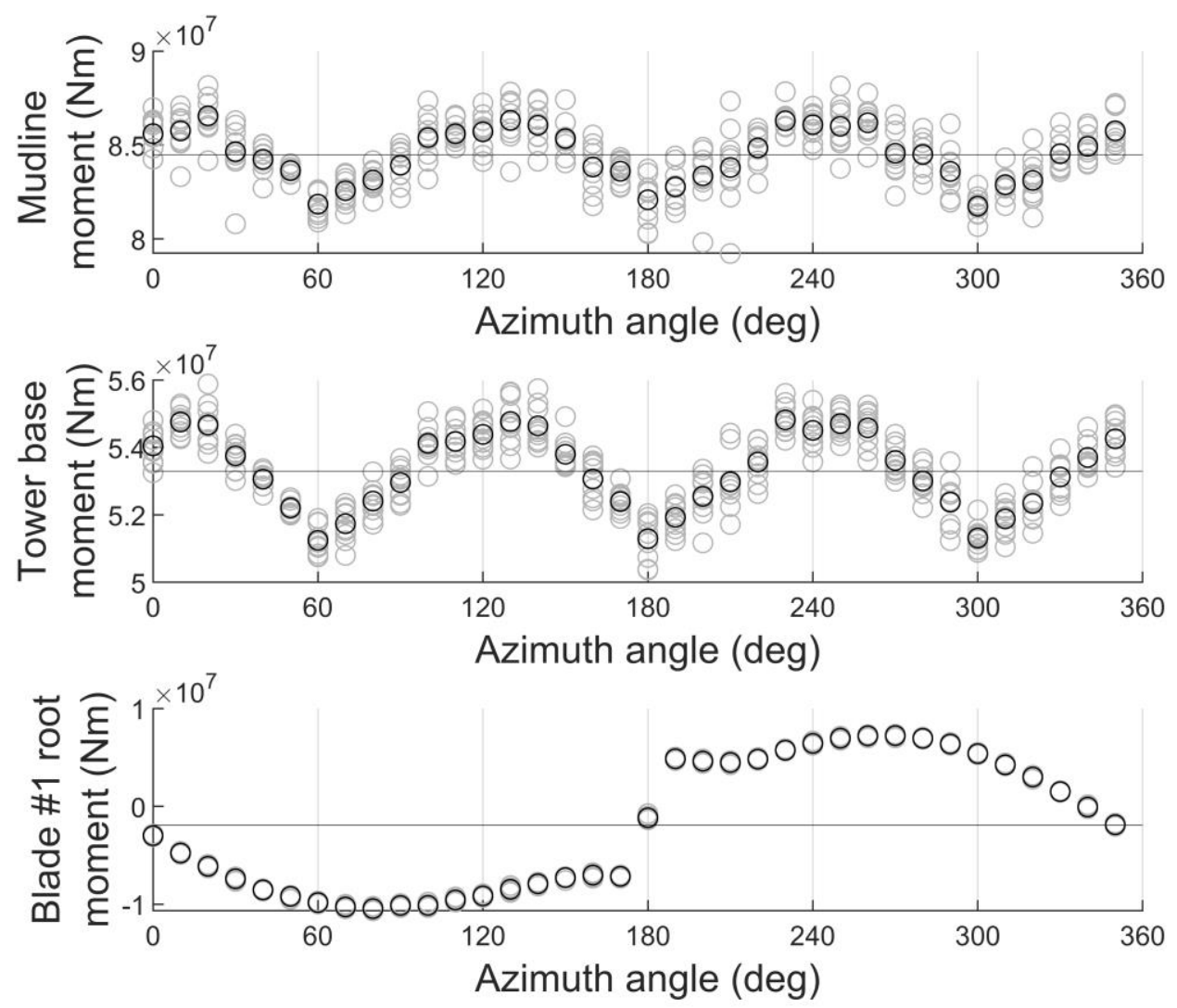

Figure 4: Acting moment as a function of the azimuth angle at the mudline (top), tower base (middle) and blade \#1 root (bottom). In each panel the mean moment is indicated by a horizontal line. 

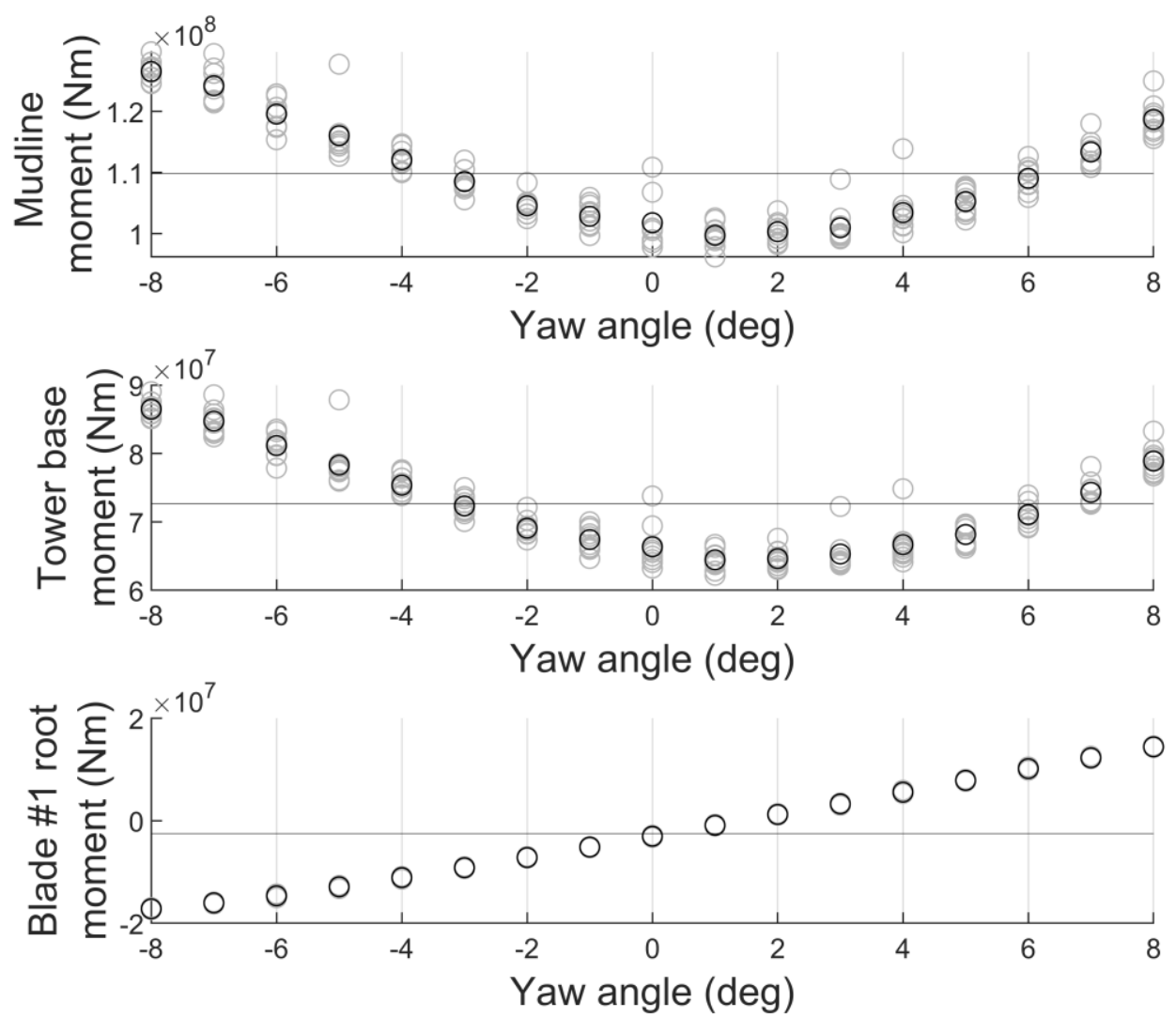

Figure 5: Acting moment as a function of the yaw angle at the mudline (top), tower base (middle) and blade \#1 root (bottom). In each panel the mean moment is indicated by a horizontal line.
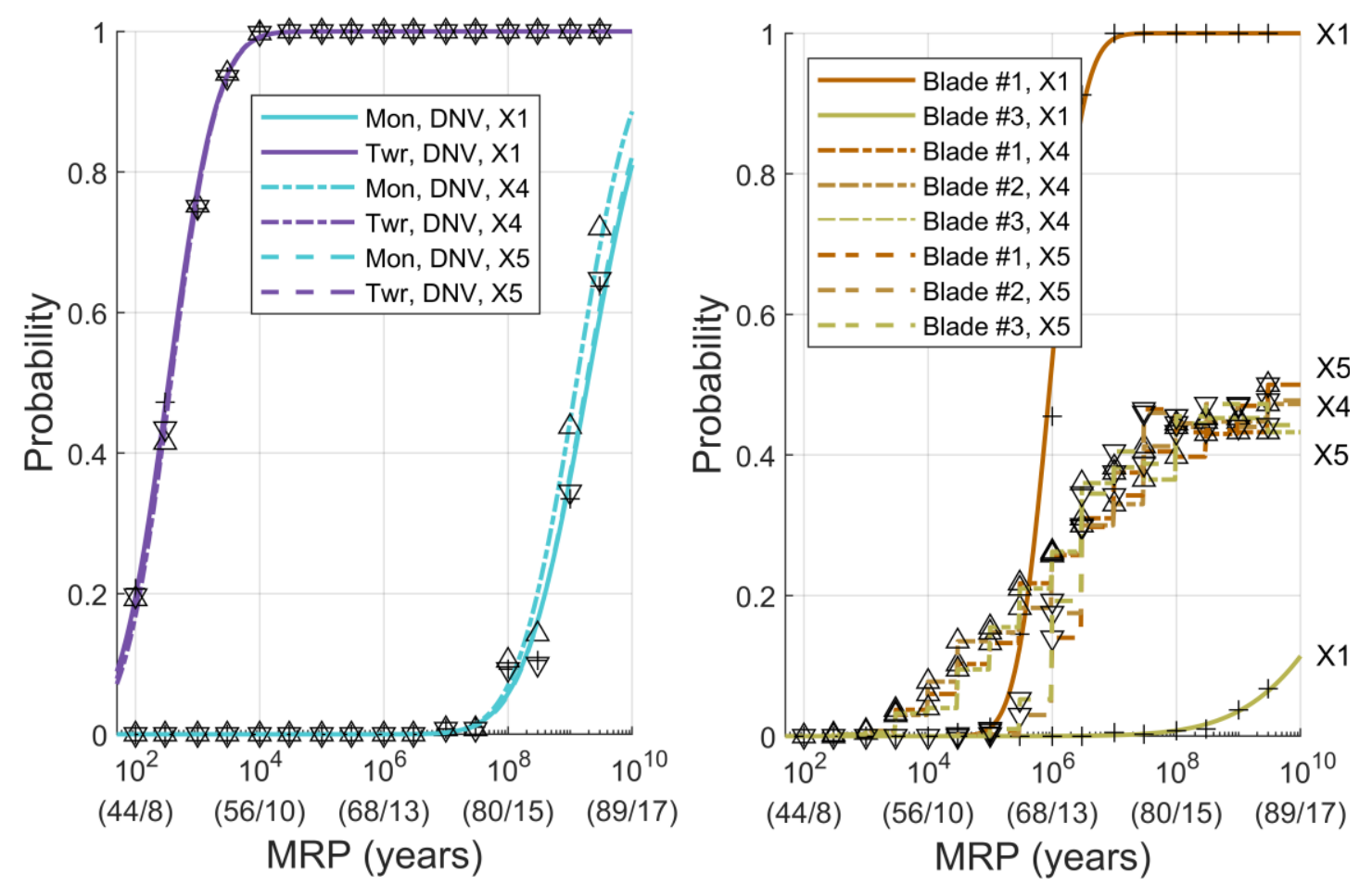

Site-specific ULS Fragility of OWT on Monopile Substructures 23/10/2019 
Figure 6: Fragility functions for the monopile and tower (left) and the blade (right) at the Ijmuiden site using the DNV limit state. Different random variable configurations are highlighted in the figure; 'Mon' represents the monopile and 'Twr' the tower. Brackets on the $\mathrm{x}$-axis labels show $\left(\mathrm{V}_{\mathrm{w}}(\mathrm{m} / \mathrm{s}) / \mathrm{H}_{\mathrm{s}}(\mathrm{m})\right)$ for a given MRP.

\subsection{Influence of different random variable configurations}

The impact of including various random variables affecting OWT capacity (e.g., those representing material and modelling uncertainties, as summarized in Table 4) on the resulting fragility functions is investigated here. The results shown in Figure 7 and Figure 8 demonstrate that, as expected, including more random variables, particularly those related to modelling uncertainty, changes the standard deviation of the fragility functions for both limit state by a similar amount but has little impact on the location of the curve. Comparing the X1 to X3 random variable configurations for the $M_{c r}$ limit state at the Ijmuiden site resulted in a <3\% change in the median and $22 \%$ increase in the standard deviation (from 2.03 to 2.27). As discussed in the previous section, inclusion of the azimuth and yaw random variables have a small impact on the location of the tower and monopile fragility functions; this is visible of Figure 7 and Figure 8 where the $\mathrm{X} 1$ and $\mathrm{X} 4$, and $\mathrm{X} 2$ and $\mathrm{X} 3$ random variable configurations result in very similar fragility functions. For the blades, including modelling uncertainty (multiplicative factors in the limit state equation) has a negligible impact on the fragility functions, see Figure 9, as the yaw and azimuth variables dominate the response.
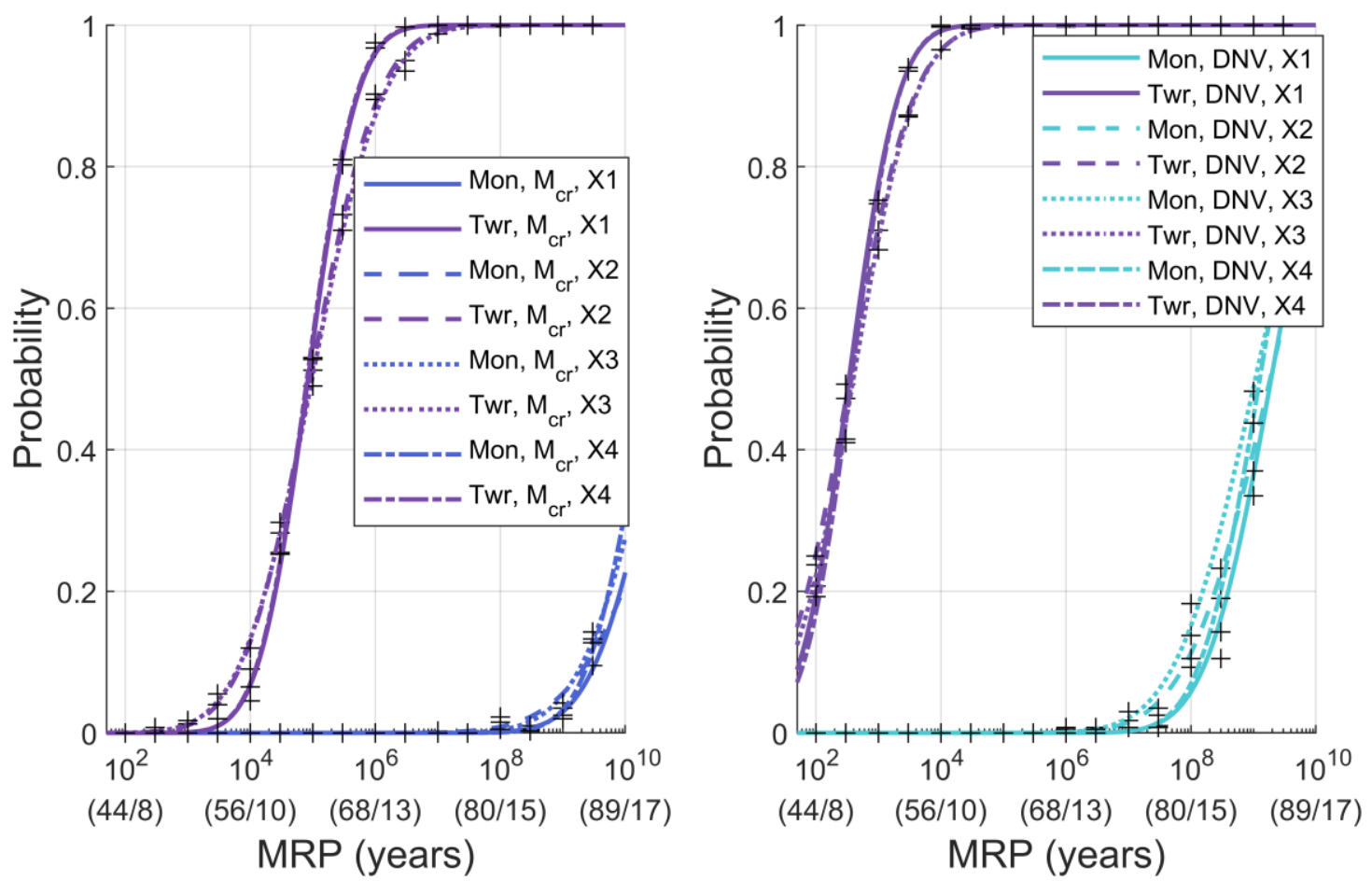

Figure 7: Fragility functions for the tower and monopile at the Ijmuiden site using the $M_{c r}$ limit state (left) and the DNV limit state (right); 'Mon' represents the monopile, 'Twr' the tower. 

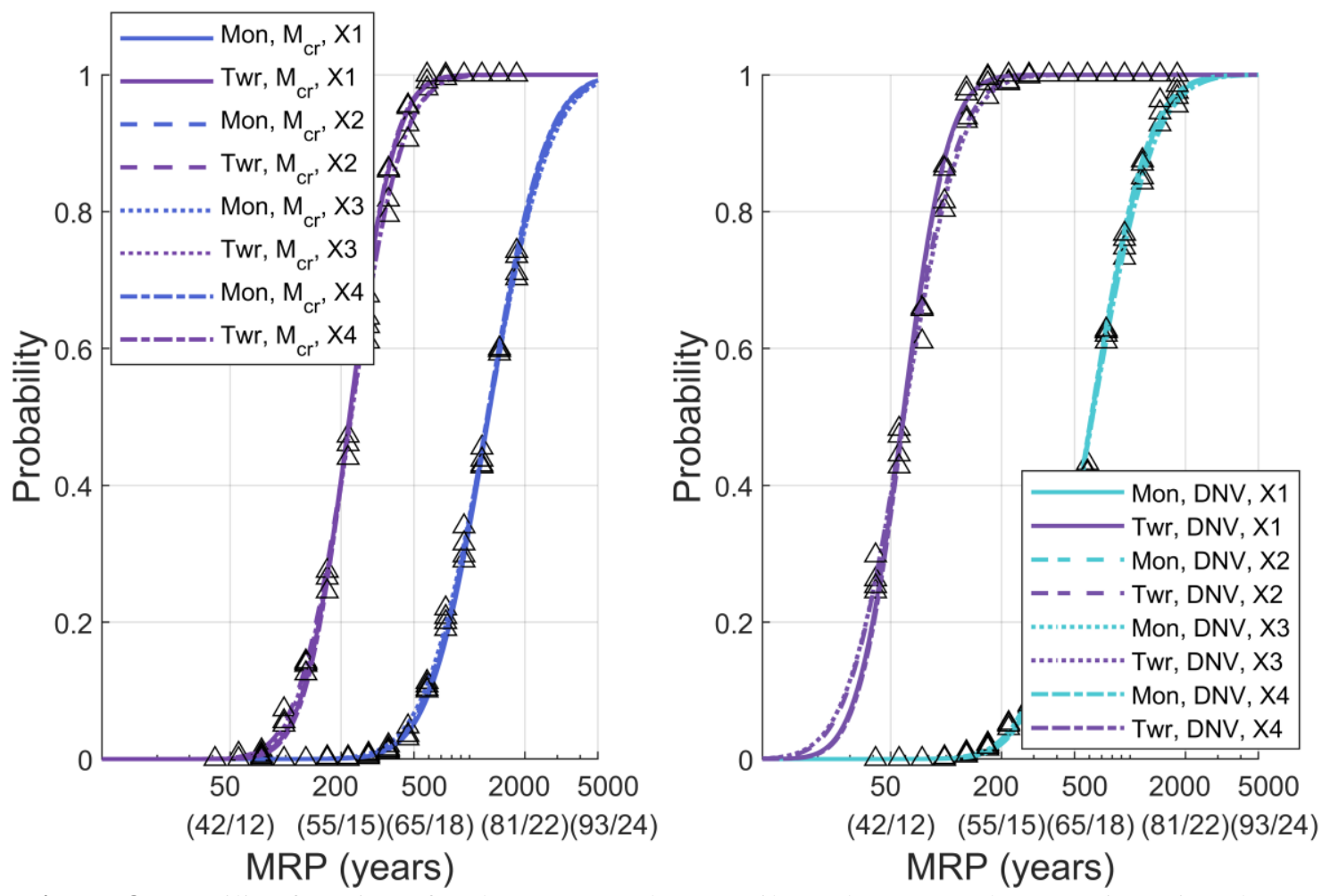

Figure 8: Fragility functions for the tower and monopile at the Massachusetts site using the $M_{c r}$ limit state (left) and the DNV limit state (right); 'Mon' represents the monopile, 'Twr' the tower.
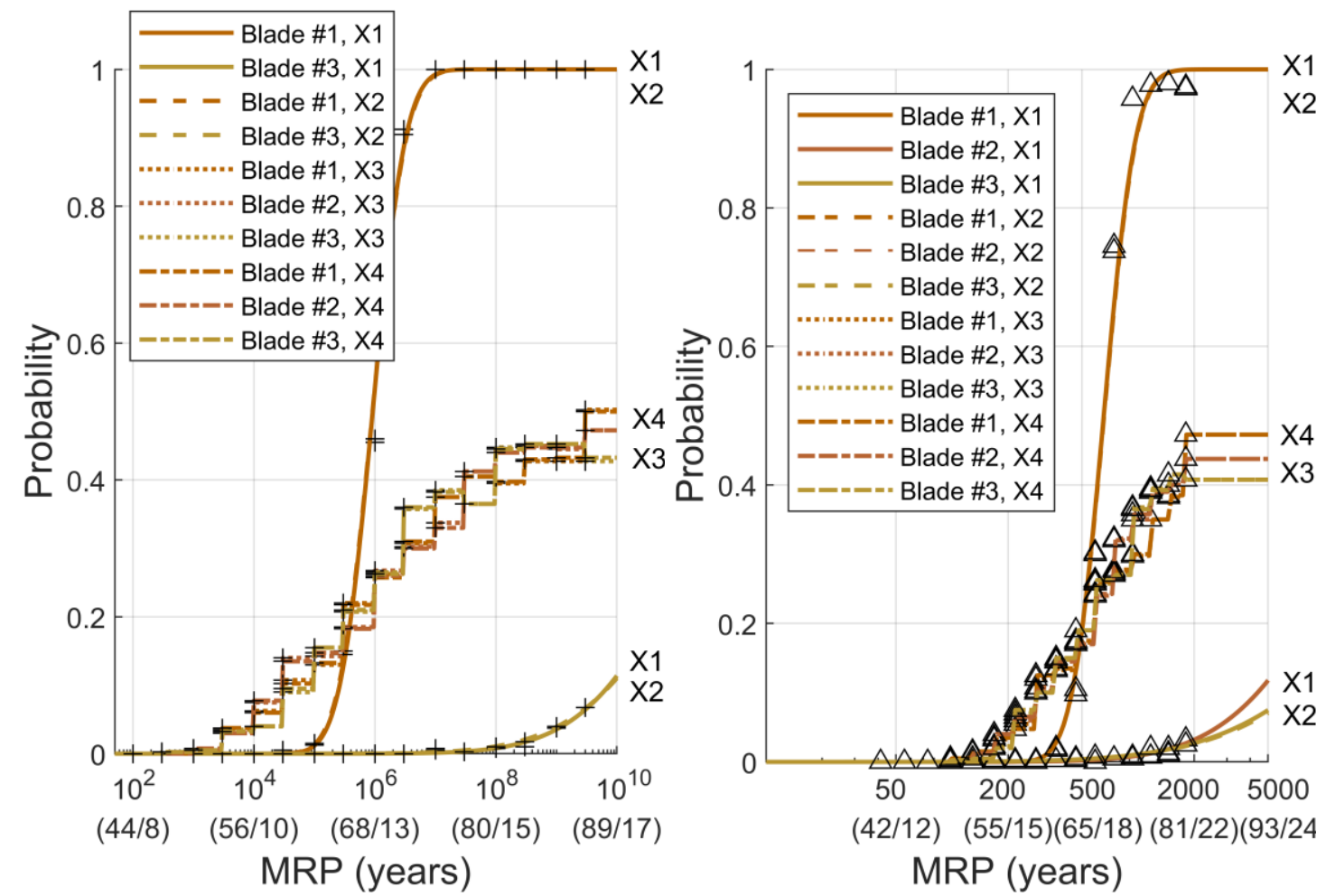

Figure 9: Fragility functions for the blades at the Ijmuiden (left) and Massachusetts (right) site. 


\subsection{Site and component limit-state comparison}

Comparing the results for different component limit states at the two sites allows one to asses which are the most critical component within an OWT. The X1 random variable configuration will be used in this section for brevity; however, findings are consistent across the various cases.

Due to the hurricane-type conditions, the Massachusetts site produces the most severe loading, resulting in relatively high probability of failure of the tower at low MRPs. For instance, probability of failures above 5\% are observed between MRP of 50 and 200 years in Figure 8 . At the Ijmuiden site, the MRP range where most components fail with a probability of more than $20 \%$ is outside the usual limits considered in the engineering design and even in probabilistic risk modelling, which usually extend up to MRPs of about 100,000 years.

The DNV and $M_{c r}$ limit states for the tower and monopile result in different fragility curves, with the $M_{c r}$ limit state resulting in lower fragility than the DNV limit state. This is particularly visible in the case of the tower and monopile fragility for the Ijmuiden site, Figure 10 (right), and can be justified by looking at the limit states in more depth. In Figure 11, the moment capacity predicted using different limit states are compared, with the DNV limit state converted into an equivalent bending moment using a membrane stress calculation. The small variations in DNV capacity are caused when the von Mises stress approaches zero and affects the characteristic buckling stress. As discussed earlier, the $M_{c r}$ limit state is calculated by subtracting a factor from the cross-section plastic moment to provide an approximate, linear fit to Eurocode 3 [48], for the NREL 5MW OWT the reduction factor is approximately 0.1. Therefore, using the $M_{c r}$ limit state, failure of the monopile will occur well above the point at which the outer fibre of the cross section first yields. On the other hand, the DNV local buckling limit state is calculated by dividing the yield stress by one plus the slenderness ratio to the power of four; therefore, it will always be less than the material yield stress, and therefore represents a more conservative interpretation of failure. The column buckling limit state is based on a similar process of reducing the buckling strength. This explains why the fragility function is shifted to lower MRP values when the DNV limit state is used. It is notable that in there is no intersection between the monopile and tower fragility functions for any of the random variable configurations. This indicates that in all cases, the tower is expected to fail before the monopile.

The fragility function for the transition piece are characterized by higher MRPs (higher than 500 years) than those corresponding to the tower and monopile fragility functions at the Massachusetts site, Figure 10 (left), and no failures in this limit state are observed at the Ijmuiden site. This indicates that, particularly when using the more conservative DNV limit state, the transition piece is unlikely to contribute to failure of the OWT in the ULS, as failure in the tower or monopile limit states will likely occur first. However, it should be noted that only one OWT geometry is used in this work, and the transition piece geometry is taken from academic research, not current industry practice (where bolted transition pieces are sometimes used in preference to the assumed grouted connection).

Fragility results for blade failure at both sites are shown in Figure 12 and indicates that failure of blade \#1, the blade with largest demand (i.e. pointing upwards) for the X1 random variable configuration, is likely to occur at more severe MRPs than those causing failure of the tower. However, as discussed in Section 5.1, fragility of the blade is sensitive to the modelling assumptions; when azimuth and yaw are treated as random variables, the failure of all blades is equally likely and occurs at lower MRPs than in the deterministic case. When using the rotor random variables, there is intersection between the tower and blade fragility functions (visible in Figure 12). This indicates that interaction between blade and tower failure hypothesized by Chen et al. [5] is plausible. Failure of the blade may reduce loading on the tower and therefore

Site-specific ULS Fragility of OWT on Monopile Substructures

23/10/2019

21 of 27 
potentially prevent its failure. However, the tower failure is generally decisive as it is observed at lower MRPs, indicating that failure of the tower independently remains the most probable scenario.
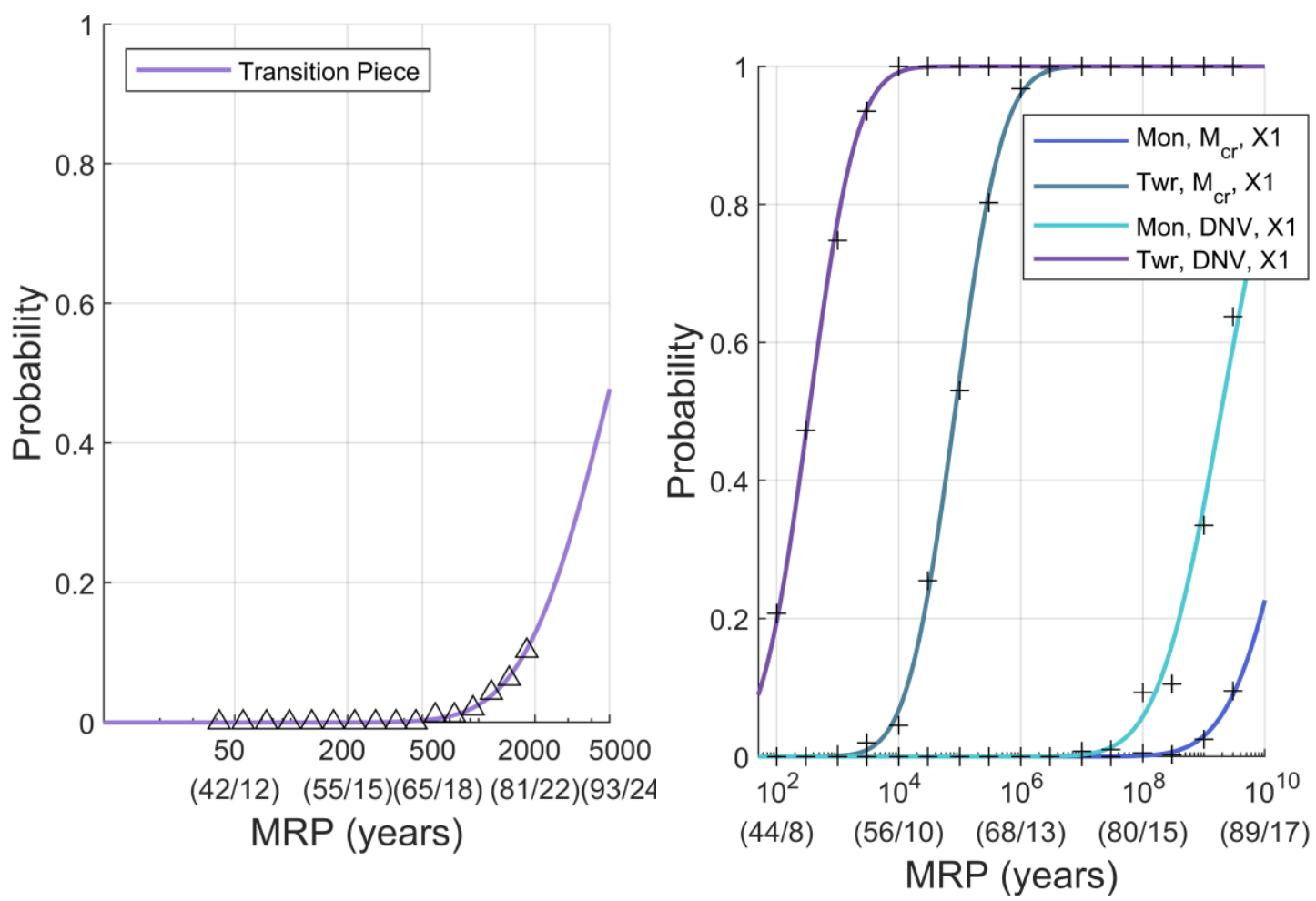

Figure 10: Fragility function for the transition piece at the Massachusetts site (left), and comparison of monopile and tower limit states at the Ijmuiden site (right); 'Mon' represents the monopile, 'Twr' the tower.
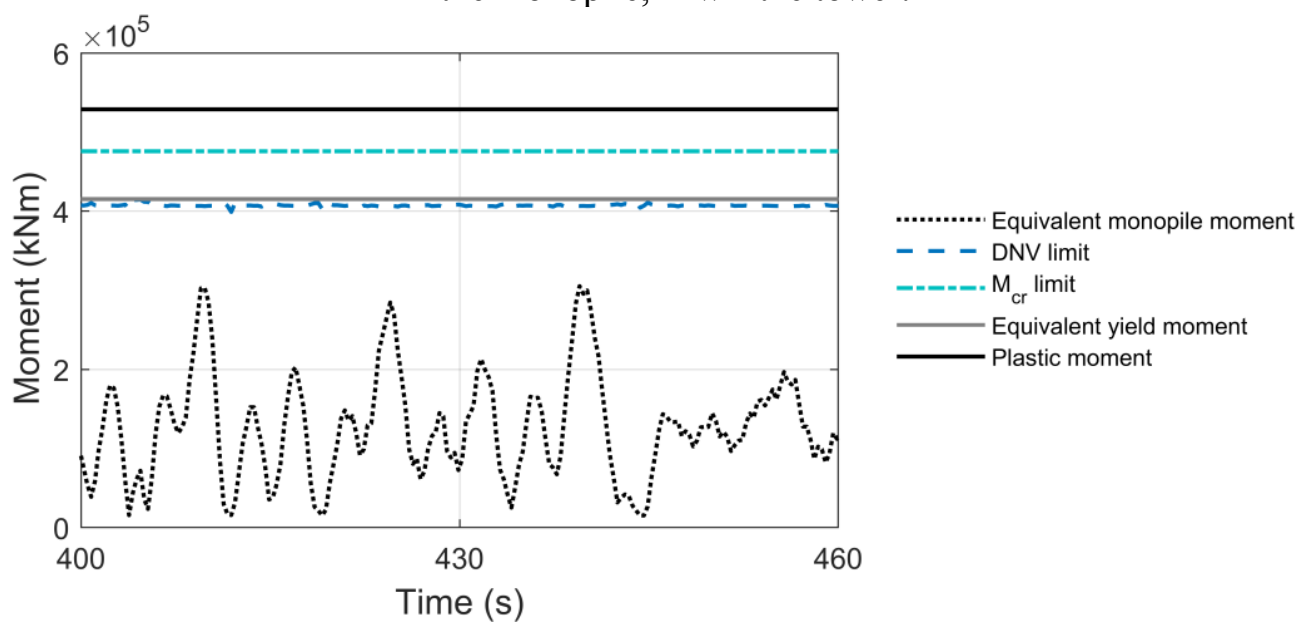

Figure 11: Comparison between the monopile limit states with all stresses converted into an equivalent bending moment. Graph is a segment from a full 600s time-history run at an MRP of $3 \cdot 10^{7}$. 

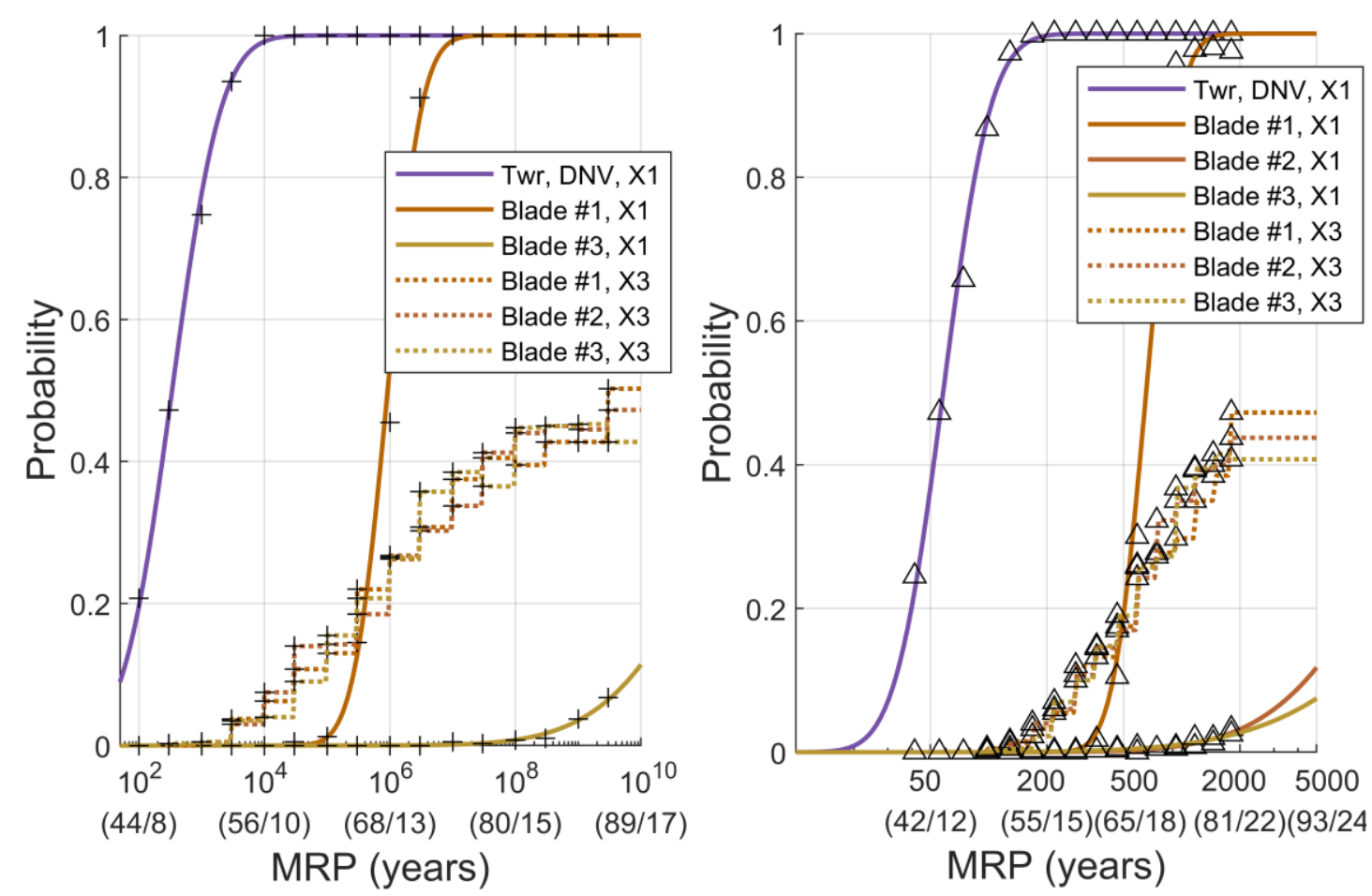

Figure 12: Fragility function for tower and blade limit states at the Massachusetts site (left), and fragility functions for tower and blade limit state at the Ijmuiden site (right); where 'Twr' represents the tower.

\section{Conclusions}

This paper represents a first step towards the development of a comprehensive probabilistic risk modelling framework for OWTs exposed to stochastic environmental conditions. Specifically, fragility functions have been developed for the main structural components of an OWT on monopile foundation exposed to extreme metocean conditions, using dynamic aeroelastic simulations and considering ULS. Fragility functions are commonly used in probabilistic risk engineering as an essential tool for assessing the vulnerability of structures/infrastructure and offer a means of communicating the probability of physical damage over a range of potential hazard intensities.

Various simplifying assumptions have been made throughout the study, particularly in assessing OWT structural response; these simplifications may affect the shape and magnitude of the computed structural fragility; however, they do not affect the framework by which fragility functions were derived as a basis for a full probabilistic risk assessment of OWTs supported by monopiles.

Findings from the considered case-study sites and structure allow one to draw some general conclusions, particularly in terms of sensitivity of the fragility analysis to a number of modelling/analysis assumptions and decisions:

- The limit state definition for the tower and monopile has a significant impact on the location of the fragility functions. Therefore, the choice of a limit state accurately describing the problem being investigated is important. For a large diameter utility scale OWT, the DNV limit state was found to be a conservative option; 
- The model uncertainties have an important impact on all limit states while the azimuth and yaw variability is only important for the blades;

- The fragility values for the monopile are extremely low, likely due to the fact that monopiles are often designed primarily to provide adequate stiffness, resulting in significant overstrength. It should also be noted that the method used here for estimating extreme conditions based on 20-30 years of continuous data is a very coarse approximation of the long MRP hazard.

- For a given MRP value, the tower was generally found to be characterized by the highest probability of failure (near to one) with respect to the other components (i.e., monopile, transition piece and blades). More in general, a system reliability approach to the overall risk associated with individual OWTs would be more appropriate, considering various correlation models between the various structural components. However, specific conclusions would still require a more comprehensive evaluation of the blade limit states.

- For the Ijmuiden site, representative of European conditions, the derived fragility functions correspond to very high MRPs, which are much larger of the typical values of interest in a probabilistic risk model or in engineering design/applications. In these conditions the fatigue limit state, not considered in this work, is expected to be more relevant in assessing OWT performance [59]. Additional studies investigating structural fragility during operational limit states are necessary to build a comprehensive view of OWT failure in the milder European conditions. Nevertheless, the ULS remains relevant for OWT that are exposed to hurricane-type conditions, such as those located on the East Coast of the USA.

In general, the computed ULS fragility is fairly low for most of the considered OWT structural components and for both sites. In fact, the OWT used in this study was not designed for these specific sites/site condition. This means that, while comparisons between the computed probabilities of failure provide valid insights, the numerical values of these probabilities should not be taken to be accurate representations of a design made for this specific site. Also, (numerical) fragility results are difficult to be validated due to the lack of empirical damage/failure data and existing research. However, similar values of the probability of failure for the tower and monopile were observed at similar MRPs for the Massachusetts site, as reported by Wei et al. [21].

These findings have potential implications for the evaluation of the overall risk profile and associated performance of offshore wind farms.

\section{$7 \quad$ Acknowledgements}

This work was supported by the UK Engineering and Physical Sciences Research Council (EPSRC), Doctoral Training Partnerships (DTP) grant EP/M507970/1 for University College London.

\section{References}

[1] Musial W, Beiter P, Schwabe P, Tian T, Stehly T, Spitsen P. 2016 Offshore wind technologies market report. US Dep Energy 2016:131. doi:DOE/GO-102017-5031.

[2] Remy T, Mbistrova A. Offshore wind in europe; key trends and statistics 2017. 2018.

[3] Govindji A-K, James R, Carvallo A. Appraisal of the offshore wind industry in japan. 2014.

[4] Nie B, Li J. Technical potential assessment of offshore wind energy over shallow continent shelf along China coast. Renew Energy 2018;128:391-9. doi:10.1016/j.renene.2018.05.081. 
[5] Chen X, Li C, Tang J. Structural integrity of wind turbines impacted by tropical cyclones: A case study from China. J. Phys. Conf. Ser., vol. 753, 2016. doi:10.1088/1742-6596/753/4/042003.

[6] International Electrotechnical Commission. IEC 61400-3. Wind turbines - Part 3: design requirements for offshore wind turbines. 2009.

[7] DNV GL. DNVGL-ST-0126. Support structures for wind turbines. 2016.

[8] British Standard Institution. BS EN ISO 19901-1: 2005 Petroleum and natural gas industries - Specific requirements for offshore structures. 2006.

[9] British Standard Institution. BS EN ISO 19902:2007+A1:2013 - Petroleum and natural gas industries - Fixed steel offhsore structurs. 2007.

[10] Hallowell ST, Myers AT, Arwade SR, Pang W, Rawal P, Hines EM, et al. Hurricane risk assessment of offshore wind turbines. Renew Energy 2018;125:234-49. doi:10.1016/j.renene.2018.02.090.

[11] Offshore wind cost reduction pathways; finance work stream. 2012.

[12] Grossi P, Kunreuther H, editors. Catastrophe modeling: a new approach to managing risk. Springer Science + Buisiness Media; 2005.

[13] Porter K, Farokhnia K, Vamvatsikos D, Cho I. Guidelines for component-based analytical vulnerability assessment of buildings and nonstructural elements, GEM Technical Report 2014-13 V1.0.0. Pavia, Italy: 2014. doi:10.13117/GEM.VULNMOD.TR2014.13.

[14] Crowley H, Silva V. OpenQuake engine book: risk v 1.0.0. Pavia, Italy: 2013.

[15] Mitchell-Wallace K, Jones M, Hillier J, Foote M. Natural catastrophe risk management and modelling. John Wiley \& Sons; 2017. doi:10.1002/9781118906057.

[16] Bakalis K, Vamvatsikos D. Seismic Fragility Functions via Nonlinear Response History Analysis. J Struct Eng 2018;144:04018181. doi:10.1061/(ASCE)ST.1943541X.0002141.

[17] Bakalis K, Vamvatsikos D. Seismic fragility functions via nonlinear response history analysis. J Struct Eng 2018;144:04018181. doi:10.1061/(ASCE)ST.1943$541 X .0002141$.

[18] Sorensen JD, Toft HS. Probabilistic design of wind turbines. Energies 2010;3:241-57. doi:10.3390/en3020241.

[19] Quilligan A, O'Connor A, Pakrashi V. Fragility analysis of steel and concrete wind turbine towers. Eng Struct 2012;36:270-82. doi:10.1016/j.engstruct.2011.12.013.

[20] Muskulus M, Schafhirt S. Reliability-based design of wind turbine support structures. Proc SRES 2015 2015;1:1-13. doi:10.13140/RG.2.1.5125.5766.

[21] Wei K, Arwade SR, Myers AT, Hallowell S, Hajjar JF, Hines EM, et al. Toward performance-based evaluation for offshore wind turbine jacket support structures. Renew Energy 2016;97:709-21. doi:10.1016/j.renene.2016.06.028.

[22] Mardfekri M, Gardoni P, Roesset JM. Probabilistic demand model based on the virtual work method and fragility estimates for offshore wind turbine support structures. Civ Eng 2011:1200-5.

[23] Mardfekri M, Gardoni P. Probabilistic demand models and fragility estimates for offshore wind turbine support structures. Eng Struct 2013;52:478-87. doi:10.1016/j.engstruct.2013.03.016.

[24] Mardfekri M, Gardoni P. Multi-hazard reliability assessment of offshore wind turbines. Wind Energy 2015;18:1433-50. doi:10.1002/we.1768.

[25] Mardfekri M, Gardoni P, Bisadi V. Service reliability of offshore wind turbines. Int J Sustain Energy 2015;34:468-84. doi:10.1080/14786451.2013.827683.

[26] De Risi R, Bhattacharya S, Goda K. Seismic performance assessment of monopilesupported offshore wind turbines using unscaled natural earthquake records. Soil Dyn Earthq Eng 2018;109:154-72. doi:10.1016/j.soildyn.2018.03.015.

[27] Ho A, Mbistrova A. The European offshore wind industry - key trends and statistics 2016. 2017.

Site-specific ULS Fragility of OWT on Monopile Substructures 
[28] Fischer T, de Vries W, Schmidt B. Upwind design basis - WP4. 2010.

[29] DNV GL. DNVGL-RP-C205. Environmental conditions and environmental loads. 2017.

[30] Wei K, Arwade SR, Myers AT. Incremental wind-wave analysis of the structural capacity of offshore wind turbine support structures under extreme loading. Eng Struct 2014;79:58-69. doi:10.1016/j.engstruct.2014.08.010.

[31] Jalayer F, Cornell CA. Alternative non-linear demand estimation methods for probability-based seismic assessments. Earthq Eng Struct Dyn 2009;38:951-72. doi:10.1002/eqe.876.

[32] Vorpahl F, Schwarze H, Fischer T, Seidel M, Jonkman J. Offshore wind turbine environment, loads, simulation, and design. Wiley Interdiscip Rev Energy Environ 2013;2:548-70. doi:10.1002/wene.52.

[33] Jonkman B, Jonkman J. FAST Readme v8.12.00a-bjj. Denver: 2015.

[34] Myers AT, Arwade SR, Valamanesh V, Hallowell S, Carswell W. Strength, stiffness, resonance and the design of offshore wind turbine monopiles. Eng Struct 2015;100:33241. doi:10.1016/j.engstruct.2015.06.021.

[35] Agarwal P, Manuel L. Incorporating irregular nonlinear waves in coupled simulation and reliability studies of offshore wind turbines. Appl Ocean Res 2011;33:215-27. doi:10.1016/j.apor.2011.02.001.

[36] Jonkman J, Robertson A, Hayman G. HydroDyn user's guide and theory manual. Denver: 2015.

[37] Kelley ND, Jonkman B. NREL/TP-500-41137. Overview of the turbsim stochastic inflow turbulence simulator. 2007.

[38] International Electrotechnical Commission. IEC 61400-1. Wind turbines part 1: design requirements. 2005.

[39] Jonkman J, Butterfield S, Musial W, Scott G. Definition of a 5-MW reference wind turbine for offshore system development. 2009.

[40] Morato A, Sriramula S, Krishnan N, Nichols J. Ultimate loads and response analysis of a monopile supported offshore wind turbine using fully coupled simulation. Renew Energy 2017;101:126-43. doi:10.1016/j.renene.2016.08.056.

[41] Resor BR. SAND2013-2569, Definition of a 5MW/61.5m wind turbine blade reference model. Albuquerque: 2013.

[42] Lee Y-S, Choi B-L, Lee JH, Kim SY, Han S. Reliability-based design optimization of monopile transition piece for offshore wind turbine system. Renew Energy 2014;71:729-41. doi:10.1016/j.renene.2014.06.017.

[43] Abdel-Rahman K, Achmus M. Finite element modelling of horizontally loaded monopile foundations for offshore wind energy converters in germany. Proc., Int. Symp. Front. offshore Geotech. ISFOG, 2005, p. 391-6. doi:10.1201/NOE0415390637.ch38.

[44] Damgaard M, Andersen LV, Ibsen LB, Toft HS, Sørensen JD. A probabilistic analysis of the dynamic response of monopile foundations: Soil variability and its consequences. Probabilistic Eng Mech 2015;41:46-59. doi:10.1016/j.probengmech.2015.05.001.

[45] Gebhardt CG, Roccia BA. Non-linear aeroelasticity: An approach to compute the response of three-blade large-scale horizontal-axis wind turbines. Renew Energy 2014;66:495-514. doi:10.1016/j.renene.2013.12.040.

[46] Tarp-johansen NJ, Kozine I, Radermakers L, Sørensen JD, Ronold K. Optimised and balanced structural and system reliability of offshore wind turbines: an account; RisoR-1420. Roskilde: 2005.

[47] Joint Committee Structural Safety. JCSS Probabilistic Model Code. 2013.

[48] British Standard Institution. EN 1993-1-6. Eurocode 3: design of steel structures - part 1-6: strength and stability of shell structures. 2009.

[49] DNV GL. DNV-OS-J101. Design of offshore wind turbine structures. 2014.

[50] British Standard Institution. BS EN 1993-1-1:2005+A1:2014. Eurocode 3 - Design of steel structures - Part 1-1: general rules and rules for buildings. 2005. 
[51] DNV GL. DNV-RP-C202. Buckling strength of shells. 2013.

[52] Lotsberg I. Structural mechanics for design of grouted connections in monopile wind turbine structures. Mar Struct 2013;32:113-35. doi:10.1016/j.marstruc.2013.03.001.

[53] DNV GL. DNVGL-ST-C502. Offshore concrete structures. 2018.

[54] Rosemeier M, Berring P, Branner K. Non-linear ultimate strength and stability limit state analysis of a wind turbine blade. Wind Energy 2016;19:825-46. doi:10.1002/we.1868.

[55] Wilkie D, Galasso C. A probabilistic framework for offshore wind turbine loss assessment. Renew Energy 2020;147:1772-83. doi:10.1016/j.renene.2019.09.043.

[56] Porter K. A beginner's guide to fragility, vulnerability, and risk 2017:103.

[57] Benjamin J, Cornell C. Probabaility, statistics and decision for civil engineers. New York: McGraw-Hill; 1970.

[58] Lallemant D, Kiremidjian A, Burton H. Statistical procedures for developing earthquake damage fragility curves. Earthq Eng Struct Dyn 2015;44:1373-89. doi:10.1002/eqe. 2522.

[59] Hübler C, Gebhardt CG, Rolfes R. Development of a comprehensive data basis of scattering environmental conditions and simulation constraints for offshore wind turbines. Wind Energy Sci 2017;2:491-505. doi:https://doi.org/10.5194/wes-2-4912017. 